\title{
Measuring symbol and icon characteristics: Norms for concreteness, complexity, meaningfulness, familiarity, and semantic distance for 239 symbols
}

\author{
SINÉ J. P. MCDOUGALL \\ University of Wales Swansea, Swansea, Wales \\ MARTIN B. CURRY \\ Sowerby Research Centre, British Aerospace, Bristol, England \\ and \\ OSCAR DE BRUIJN \\ University of Wales Swansea, Swansea, Wales
}

\begin{abstract}
This paper provides rating norms for a set of symbols and icons selected from a wide variety of sources. These ratings enable the effects of symbol characteristics on user performance to be systematically investigated. The symbol characteristics that have been quantified are considered to be of central relevance to symbol usability research and include concreteness, complexity, meaningfulness, familiarity, and semantic distance. The interrelationships between each of these dimensions is examined and the importance of using normative ratings for experimental research is discussed.
\end{abstract}

There is now a growing body of research examining the characteristics considered important in determining how easy symbols ${ }^{1}$ are to use. The catalyst for these studies has been the expansion in the use of symbols to convey information instead of written messages. Symbolic information is now commonplace in airports, in railway stations, and on roads (Arnstein, 1983; Zwaga \& Easterby, 1984). It also forms an integral component of computer interfaces and serves to convey functional information on a variety of equipment such as cars, farm equipment, fighter aircraft, and naval tactical data systems (Cahill, 1975; Deaton, Barnes, Kern, \& Wright, 1990; Flach \& Vicente, 1989; P. Green, 1993; Kirkpatrick, Dutra, Lyons, Osga, \& Pucci, 1992). Symbols are used not only because they provide a universal, international, mode of communication, but also because they can often be recognized and used more quickly than their word equivalents (Ellis \& Dewar, 1979; Muter \& Mayson, 1986).

Although symbols appear to be an effective means of communicating information, they can often be interpreted in a number of different ways, and we lack a clearly defined set of rules that would enable us to disambiguate

This research was part of the Effective Symbology Project, which is ongoing research supported by a grant from British Aerospace plc (Grant SRC/UOS/060495). Correspondence should be addressed to S. J. P. McDougall, Psychology Department, University of Wales Swansea, Swansea SA2 8PP, Wales (e-mail: s.mcdougal1@ swansea.ac.uk). their meaning in the same way as spoken or written communication. This means that when designers are developing symbols, they need to make them as easy to understand and use as possible. One way of ensuring this is to draw on the numerous guidelines that delineate good symbol design practice (e.g., Bocker, 1993; Gittens, 1986) or to use symbol listings drawn up by international standards organizations (e.g., British Standards Institution 1989: International Standards Organisation [ISO], 1982, 1994). The benefits that these design aids can bring, however, is necessarily constrained by what we know about symbol design. If symbol design is to progress, we need to know more about why some symbols are easier to use than others. This has been the goal of research in this area.

A major obstacle facing researchers attempting to answer this question has been the difficulties in quantifying symbol characteristics so that they can be experimentally controlled. A good way of controlling symbol characteristics experimentally is to obtain subjective ratings of each characteristic. Although there has been a long tradition in psycholinguistic research of using normative ratings to control item characteristics for words (e.g., Benjafield, Frommhold, Keenan, Muckenheim \& Mueller, 1993; Friendly, Franklin, Hoffman, \& Rubin, 1982; Gilhooly \& Logie, 1980; Paivio, Yuille, \& Madigan, 1968; Quinlan, 1992) and pictures (Martein, 1995; Sanfeliu \& Fernandez, 1996; Snodgrass \& Vanderwart, 1980; van Schagen, Tamsma, Bruggemann, Jackson, \& Michon, 1983), no normative ratings for symbols have yet been produced. As a result, researchers have been forced to 
develop their own, sometimes idiosyncratic, sets of symbols for experimentation. This has had the advantage that symbols are often very well suited for the experimental purpose for which they have been designed, but has the disadvantage that differences in the symbol characteristics being manipulated are more often the result of the judgment of individual experimenters rather than of appropriate experimental control. This problem is addressed in the present paper by providing normative ratings for symbol characteristics.

\section{Symbol Characteristics}

The choice of symbol characteristics to be rated was determined in light of an extensive review of the literature (McDougall, Curry, \& de Bruijn, 1996). This review identified a number of symbol characteristics of central concern to researchers. These included concreteness, visual complexity, meaningfulness, familiarity, and semantic distance. Current research on each of these characteristics is briefly reviewed below. This is followed by a description of the way each of these characteristics was quantified. Symbol characteristics that are self-evident (such as color) or those that can be defined only in relation to other symbols in a display (such as discriminability, distinctiveness, and configurality) are not included for consideration here.

Concreteness and visual complexity. One of the strongest claims made for symbols, and particularly for icons, is that they are easier to use because they are concrete. Concrete symbols tend to be more visually obvious because they depict objects, places, and people that we are already familiar with in the real world (Rogers, 1989; Stammers \& Hoffman, 1991; see, e.g., Items 36, 90,176 , and 214 in the Appendix). Abstract symbols, in contrast, represent information using graphic features such as shapes, arrows, and so on (see Items 79, 119, and 185). Performance advantages for concrete symbols over abstract symbols have been found, and this appears to be consistent with the visual obviousness hypothesis (A. J. K. Green \& Barnard, 1990; Rogers \& Oborne, 1987; Stammers \& Hoffman, 1991).

One of the reasons why concrete symbols are more visually obvious may simply be because the extra detail provided in concrete symbols makes them easier to use. Research carried out by Garcia, Badre, and Stasko (1994) has confirmed that concrete symbols used in experiments contain more detail than abstract symbols. Using a measure of visual complexity, they found that concrete symbols created for a number of studies were more complex than the abstract symbols used (i.e., Arend, Muthig, \& Wandmacher, 1987; Rogers, 1986; Rohr \& Keppel, 1985; Stammers, George, \& Carey, 1989). On this basis, it would appear that concrete symbols are necessarily more complex in order to provide the detail required.

In contrast, however, design guidelines typically suggest that the design of symbols or icons should be kept as simple as possible. As far back as 1970, Easterby suggested that designers follow a "simplicity principle" be- cause he felt that extra detail did not contribute to unambiguous and rapid interpretation of a symbol. This minimalist design approach has been endorsed by Rogers (1989). In a recent study, Byrne (1993) created a series of simple and complex symbols and examined the effect of symbol complexity on search performance. Search times were found to be shorter for simple, as opposed to complex, symbols. Byrne's findings seem to support the proposition that simplicity is the best policy in symbol design, particularly if response time is an important consideration.

These two strands of research pose an interesting dilemma for applied practice. While some researchers would seem to recommend the increase of detail to promote symbol efficacy, others advocate the removal of detail to achieve exactly the same objective. The reason for these two sets of conflicting recommendations may well be that researchers have confounded concreteness with complexity when devising symbol sets for experimentation. This paper will address this possibility by examining the correlation between rated concreteness and complexity. A strong correlation between these two dimensions would provide support for the notion that concreteness and complexity are parallel characteristics. If no correlation is found, this would suggest that these two symbol characteristics have indeed been confounded in prior research.

Concreteness and meaningfulness. Other researchers have focused on the fact that concrete symbols are more meaningful than abstract symbols. The relationship between concreteness and meaningfulness has perhaps been most thoroughly examined by Rogers (1986, 1989; Rogers \& Oborne, 1987). She assessed participants' performance using six types of symbols that varied in degree of concreteness. As can be seen from Figure 1, symbols consisted of (1) abstract symbols (Set 1), (2) concrete analogies associated with action (Set 2), (3) concrete objects that are operated on in some way (Set 3 ), and (4) combinations of the above (Sets 4,5 , and 6 ).

When participants were asked to match written functions to symbols, performance was found to be poor for abstract symbols and even worse when concrete analogies were used to depict functions. Rogers therefore concluded that a critical determinant of a symbol's usability was the meaningfulness of the relationship between what was depicted in the symbol and the function it refers to, rather than its concreteness per se. The nature of the relationship between meaningfulness and concreteness was therefore examined in this study.

Earlier research suggests that the relationship between abstract symbols and their functions may be more diffuse than that for concrete symbols (Howell \& Fuchs, 1968; Jones, 1983). Jones asked participants in her study to draw symbols for function names that she had provided. The drawings produced for each concept were then sorted into categories by judges. Jones found that the number of categories for each function was correlated with concreteness. As each function became more abstract, the meaning of each drawing appeared to grow more diffuse, 


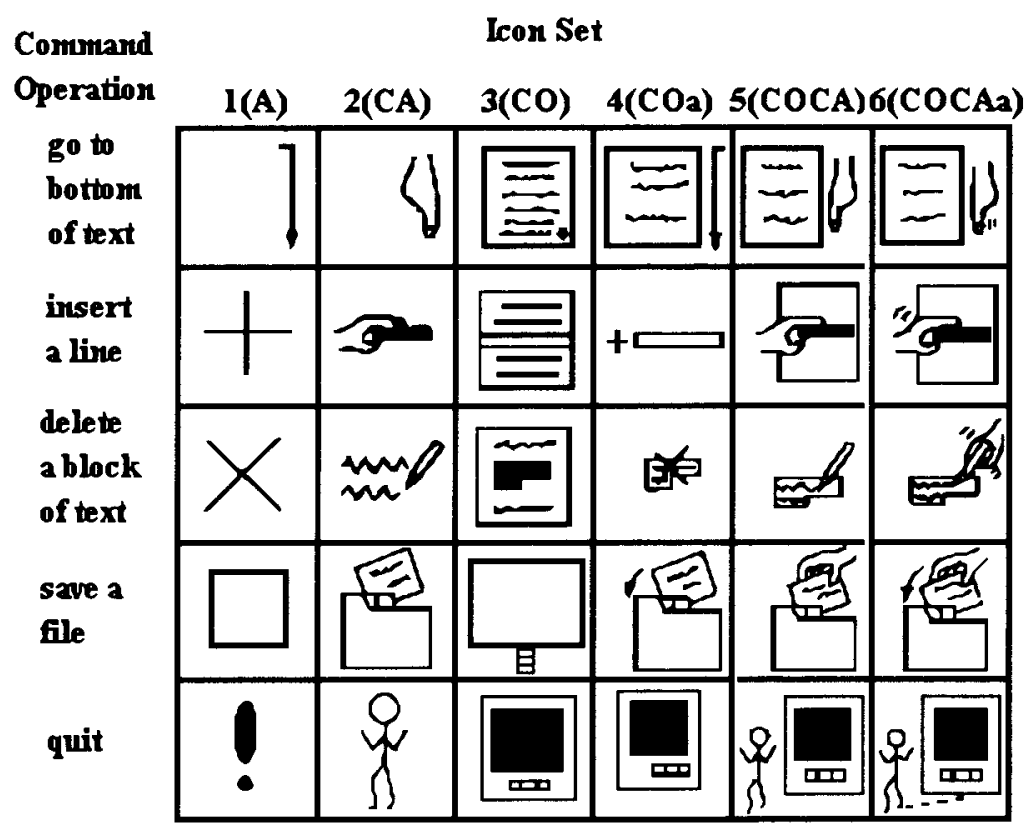

Figure 1. Six types of symbols used by Y. Rogers. A, abstract symbols; CA, concrete analogy associated with action; $\mathrm{CO}$, concrete object operated on. From Pictorial Representation of Abstract Concepts in Relation to Human Computer Interaction (p. 141), by Y. Rogers, 1988, unpublished doctoral dissertation, University of Wales Swansea. Reprinted with permission.

resulting in more categories. This suggests that the meaning for abstract functions may be less stereotypical than for concrete functions and may affect the ease with which mappings may be made between symbol and function. This possibility was examined further in this study. Participants were asked to guess the meaning, or function, of each symbol they were shown. It was then possible to assess the extent to which there was agreement between participants about possible symbol meanings (see discussion of concept agreement, below) and to evaluate the relationship between concreteness and meaning stereotypicality.

Semantic distance. Semantic, or articulatory, distance is a measure of the closeness of the relationship between the symbol and what it is intended to represent. In some cases the relationship is very clear (e.g., when a picture of a printer is used to denote the "print" function in a word processing package; see Figure 2). In other cases the relationship is less obvious (e.g., the triangle used to represent a "hazard ahead," also in Figure 2). In this case the relationship between what is depicted in the symbol and the function it represents is much weaker, and it is only our familiarity with the symbol that allows us to interpret it.

A number of classification systems have been developed in order to attempt to characterize the different relationships that obtain between symbols and their functions. An early taxonomy proposed by Peirce (see Hartshorne, Weiss, \& Burks, 1958) contains three categories of signs (or symbols), each of which relates to a different type of symbol-function relationship: (1) icon-- a direct symbol-function relationship (see Figure 2A); (2) index-an implied rather than a direct symbolfunction relationship (see Figure 2B); and (3) symbol-an arbitrary relationship between symbol and function (see Figure 2C).

Several other classification systems have been developed along similar lines (see, e.g., Blattner, Sumikawa, \& Greenberg, 1989; Familant \& Detweiler, 1993). Although these classification systems are meant to represent different types of symbol-function relationship, they also appear to represent a continuum of the closeness of the relationship. For example, in Peirce's taxonomy, icons represent the closest relationship, index a moderately close relationship, and symbol a very distant relationship. We therefore propose that the symbol-function relationship can be very effectively treated as a semantic distance continuum. A similar approach to this has been adopted by Moyes and Jordan (1993), who emphasized the importance of closeness of the symbol-referent relationship in determining usability. Subjective ratings along a

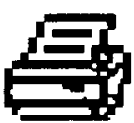

(A) direct

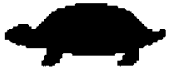

(B) implied

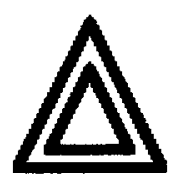

(C) arbitrary
Figure 2. Symbols with direct, implied, and arbitrary relationships to their function referent. Note-Figure $2 \mathrm{~A}$ is reprinted with kind permission from the Microsoft Corporation. 
continuum therefore provide a good indication of the closeness of the symbol-function relationship.

It is important to note that semantic distance may not necessarily be synonymous with a symbol's meaningfulness. For example, in Figure $2 \mathrm{C}$, the hazard sign may be meaningful to drivers because of their familiarity with it, despite the fact that the semantic distance between symbol and referent is large. The interrelationships between these three dimensions - meaningfulness, familiarity, and semantic distance-were therefore examined in this study.

Familiarity. Familiarity reflects the frequency with which symbols are encountered. This property is thought to be an important determinant of usability. It is evident that user performance improves dramatically as a result of learning symbols and signs (see, e.g., Brems \& Whitten, 1987; Margono \& Shneiderman, 1987). It is also clear that the effects on performance of other symbol characteristics may diminish as symbol-function relationships are learned. For example, performance differences between concrete and abstract symbols have been found to lessen with familiarity (Arend et al., 1987; Stammers et al., 1989). Similarly, the beneficial effects of use of color in displays has been found to diminish over time as novice users become more expert (Christ \& Corso, 1982). Despite such findings, it is interesting to note that although overall performance may improve in response to familiar complex and simple symbols, response times remain slower to complex symbols even after they have been learned (Byrne, 1993). To summarize, the effects of some symbol characteristics on performance, such as color and concreteness, diminish as symbols become more familiar but others, such as complexity, do not. The interrelationships between familiarity and other symbol characteristics were therefore examined in this study.

On the basis of our brief review, it is apparent that each of the symbol characteristics described may have an effect of symbol usability. This paper will therefore provide rating norms for these characteristics to enable their effects on user performance to be systematically investigated. Possible interrelationships between symbol characteristics are also examined. Of particular interest is the possibility that there is no necessary relationship between symbol concreteness and complexity and that these two factors may have been confounded in previous research.

\section{METHOD}

\section{Participants}

All participants were students from the University of Wales Swansea who were paid $£ 3$ for their participation. A total of 200 students took part in this study; 40 students each rated one of the five dimensions of interest-concreteness, complexity, meaningfulness, familiarity, and semantic distance. Since gender differences in ratings have been found in previous norms for words (Benjafield et al., 1993; Benjafield \& Muckenheim, 1989; Friendly et al., 1982; Toglia \& Battig, 1978), equal numbers of women and men rated each dimension.

\section{Development of the Symbol Set}

Symbols were chosen from a wide variety of sources in order to ensure that they were representative of the broad spectrum of ap- plications in which symbols are currently used. These included symbols for use on electrical equipment (e.g., ISO, 1989; International Electrotechnical Commission, 1973), public information symbols (e.g., American Institute of Graphic Arts, 1982; ISO, 1990), military symbology (e.g., North Atlantic Treaty Organization, 1989), Internet websites (e.g., $\mathrm{W}_{3} \mathrm{C}, 1996$ ), vehicle and aircraft controls and displays (ISO, 1995), and computer interfaces (Microsoft Corporation, 1989, 1995). Initially a large corpus of symbols was formed and a semirandom procedure was used to select a subset of items. It was decided that, for research purposes, a reasonably even distribution of concrete and abstract items, visually complex and simple items, and familiar and unfamiliar items would be desirable. Symbols were therefore chosen from the corpus in order to ensure that each type of symbol was approximately evenly represented. Ten volunteers were asked to classify the symbol corpus into groups in accordance with their concreteness, complexity, and familiarity. Each volunteer was asked to classify items into three classifications denoting both ends of the continuum and a midpoint (e.g., concrete, abstract, moderately concrete). The numbers falling into each classification on the basis of the three symbol characteristics were as follows: concrete $(n=68)$, moderately concrete $(n=61)$, abstract $(n=69)$, complex $(n=46)$, moderately complex $(n=65)$, simple $(n=69)$, familiar $(n=67)$, moderately familiar $(n=78)$, and unfamiliar $(n=54)$. Although care was taken to ensure that there was as even a spread as possible of symbols, some types of symbols are underrepresented. For example, abstract symbols that are also complex and familiar arise relatively infrequently. This is also the case for symbols that might be characterized as concrete, simple, and unfamiliar.

Symbols were also chosen to reflect the wide variety of functions for which they are currently used. Symbols were divided roughly into four categories of use: computers $(n=77)$, traffic and public information $(n=48)$, industrial $(n=69)$, and household goods $(n=$ 50). Computer symbols included icons and symbols used in computer software packages (e.g., Items 48 [color area] and 34 [center alignment] and on Internet websites (e.g., Items 201 [shopping] and 233 [webcrawler]. Traffic and public information symbols included signs used on roads, at railway stations, and airports, as well as symbols used in cars (such as Items 112 [headlamp cleaner] and 40 [choke]). Industrial symbols included those used to signify functions on industrial machines or processes (e.g., Items 80 [engage pile-raising roller], and 129 [laminate]). Industrial symbols also included a small number of military symbols (e.g., Item 70 [diver]). Symbols for household goods encapsulated those found on video recorders (Item 91 [fast forward]), washing machines (Item 185 [rinse]), refrigerators (Item 216 [three-star freezing compartment]), and cameras (Item 238 [zoom]).

\section{Procedure}

Symbols were presented to participants in booklets. Each booklet consisted of 20 pages, each page with 12 symbols printed in random order. Alongside each symbol was a 5-point rating scale. Pages were assembled into booklets in accordance with a Latin square design to ensure that each participant was presented with the symbols in a different order. Booklet covers contained a brief description of the dimension that participants were being asked to rate and instructions about how they should carry out the rating process.

Concreteness. Instructions for concreteness ratings were similar to those adopted in previous studies in which concreteness ratings have been obtained (Gilhooly \& Logie, 1980; Paivio et al., 1968; Spreen \& Schulz, 1966). Symbols were to be regarded as concrete if they depicted real objects, materials, or people; those that did not were to be regarded as abstract $(1=$ definitely abstract, $5=$ definitely concrete).

Complexity. Complexity ratings were obtained using instructions similar to those adopted by Snodgrass and Vanderwart (1980) when obtaining complexity ratings for black-and-white line drawings. Complexity was defined as the amount of detail or intricacy 
in the symbol. Participants were instructed to rate the complexity of each symbol on a 5-point scale $(1=$ very simple, $5=$ very complex $)$.

In contrast to other studies on symbol characteristics, an attempt was made to quantify the complexity of symbols using a complexity metric. Complexity metrics are typically applied to whole displays rather than individual symbols (Tullis, 1983), but Garcia et al. (1994) recently developed a metric that can be applied to individual symbols. Their metric is based on adding up the number of components present in a symbol. These components consist of the numbers of horizontal, vertical, and diagonal lines, and the number of closed figures, open figures, and letters present in the symbol. It was this measure of complexity that Garcia et al. used to assess the complexity of concrete and abstract symbols employed in previous studies (see above). In the present study, one of the authors (M. B. C.) used the metric to obtain a measure of the complexity of each of the symbols in our set. This was then used to assess the validity of the complexity ratings we had obtained.

Familiarity. Since it was not possible to obtain measures of frequency of occurrence of symbols in the same way as might be possible for words, participants were asked to rate their perceived familiarity with symbols. Familiarity was defined in terms of the frequency with which symbols had been encountered by participants. For example, most people would find the symbol used to indicate men's restrooms as very familiar (despite slight variations in the symbol used). Other symbols may have never, or only rarely, been encountered before. A 5-point rating of scale was used $(1=$ very unfamiliar, $5=$ very familiar

Meaningfulness, concept agreement, and name agreement. Participants were asked to rate how meaningful they perceived symbols to be. They were told that symbols that conveyed a great deal of meaning should be given a high rating ( 4 or 5 ) and those that conveyed little meaning should be given low ratings ( 1 or 2 ). After rating each symbol, participants were asked to state briefly what they felt the meaning of the symbol to be. Those who had provided a rating of 1 (completely meaningless) for an item were not required to provide a meaning for that symbol.

The percentage of participants who were able to ascertain the correct function, or meaning, of symbol was calculated. Similar measures of agreement have been obtained in the past for picture norms (Lachman \& Lachman, 1980; Snodgrass \& Vanderwart, 1980). Strict criteria were adopted for counting instances of correct picture names. Where names were not identical to an established name, they would be counted as incorrect. This included misspellings of the picture name, abbreviations (such as TV for television), and elaborations. The use of such a strict criterion was felt to be inappropriate for symbols since it is the identification of function, rather than the correct label, that is important in determining participants' performance. As a result, we adopted the measure of concept agreement suggested by Martein (1995), which allows for the inclusion of synonyms, common abbreviations, elaborations, multiple names, diminutives, and dialect words. A similar measure of concept agreement has subsequently been employed by Snodgrass and Yuditsky (1996). It should be noted that while high levels of concept agreement are possible for picture names, particularly if the pictures represent common objects, lower levels of agreement might be expected for symbol functions since symbols are inherently more ambiguous.

A further measure, name agreement, was also obtained. This was important when the possible function most commonly assigned to the symbol by participants differed from the given function. Where concept agreement and name agreement differ, this indicates that there is not a good fit between the designated symbol-function agreement and that other, better, possibilities exist.

Semantic distance. As we have already noted, symbols vary in the closeness of the relationship between the graphic and the function being represented. In some cases the relationship is fairly direct (e.g., the printer shown in Figure 2 used as a symbol for printing documents from word processors). In other cases the relationship is much less direct (e.g., the triangle used to indicate "hazard ahead," also in Figure 2). The "semantic distance" between function and symbol might be regarded as quite small in the first case, but much larger in the second case.

Participants were given these examples in order to explain the concept of semantic distance and then asked to provide ratings for the closeness of each of the 240 symbols to their functions ( $1=$ not closely related, $5=$ very strongly related .

\section{RESULTS AND DISCUSSION}

\section{Symbol Information}

The Appendix provides an alphabetical index of symbols used in this study to allow symbols to be accessed using their function name. Accompanying the symbols in the Appendix are the mean ratings for each symbol characteristic. The complexity metric for each symbol (calculated using the method developed by Garcia et al., 1994) is also listed, as are percentage values for concept agreement and name agreement. Where the most common meaning given for a symbol does not match the given function name (i.e., where name agreement exceeds concept agreement), the alternative is shown at the bottom right-hand corner of the entry for that symbol. Where a value of $2.5 \%$ is quoted for name agreement, only one person provided an alternative meaning, or there was no agreement over alternative meanings (a series of individuals provided different alternatives). Where this is the case, no alternative meaning is provided at the bottom of the entry for that icon.

\section{Reliability and Validity}

Reliability of the ratings was evaluated using splithalf reliability measures. Each group of 40 participants was divided into two subgroups of 20 , with equal numbers of women and men in each subgroup. New mean ratings were then calculated for each symbol, and the correlations between subgroup ratings for symbols were calculated. Split-half reliabilities were all above .90 (concreteness $=.95 ;$ complexity $=.94 ;$ familiarity $=.95$; meaningfulness $=.96$; semantic distance $=.95$ ). This indicates considerable between-group stability in the ratings obtained.

Since to our knowledge no ratings have previously been obtained for symbols, the validity of our ratings could not be assessed by comparison with previous work. However, a measure of the external validity of the complexity ratings could be obtained by using the metric developed by Garcia et al. (1994). The distribution of values obtained using the metric was positively skewed, and the data were therefore transformed using a $\log _{10}$ transformation before correlating the metric with the ratings data. The correlation obtained was high $\left(r_{\mathrm{s}}=.73\right)$, suggesting that the metric and ratings were tapping a similar construct.

\section{Summary Statistics}

Table 1 presents summary statistics for each of the ratings obtained. Included are the overall means, standard deviations, medians, and measures of skew. The range of 
values obtained from participants is indicated by minimum and maximum values. Mean ratings were generally grouped around the midpoint of the 5-point rating scale, and dispersion of scores about the mean was similar for all rated symbol characteristics. With the exception of the complexity metric and concept agreement, all variables were normally distributed. Both the complexity metric and concept agreement were transformed using a $\log _{10}$ transformation to reduce skew before further analyses were conducted.

\section{Interrelationships Between Symbol Characteristics}

Correlations between symbol ratings and measures of concept agreement, name agreement, and the complexity metric are shown in Table 2.

Concreteness and complexity. One aim of this study was to examine the possibility that prior research may have confounded the effects of concreteness and complexity. This was suggested by the contrast between research and design practice. An assumption implicit in the research literature is that concrete symbols are easier to use because of the extra visual detail they contain. When Garcia et al. (1994) measured symbol complexity using a metric, it was found that concrete symbols used in a number of experiments were indeed consistently more complex than the abstract symbols presented. However, design guidelines often argue that simplicity makes symbols more usable and that detail should be removed rather than added (Easterby, 1970; Rogers, 1988). Given current design practice, it therefore seems plausible to suggest that there is no necessary relationship between concreteness and complexity.

A strong correlation between visual complexity and concreteness would provide support for the notion that concreteness and complexity are inevitably intertwined. The absence of a correlation would suggest that concrete symbols can also be simple. Table 2 shows that there was no significant correlation between the two variables and that concreteness and complexity are therefore two separable dimensions. It also suggests that concreteness and complexity may have been confounded in some previous studies.

A number of examples in the Appendix show that it is possible to keep extra visual detail (and hence complexity) to a minimum while utilizing users' preexisting world knowledge (e.g., Items $24,94,96,114,156,202$, and 214). On this basis it would seem that the use of a visual

Table 1

Summary Statistics for All Symbol Characteristics

\begin{tabular}{lcccccc}
\hline \multicolumn{1}{c}{ Measure } & $M$ & Median & $S D$ & Min & Max & Skew \\
\hline Concreteness & 3.26 & 3.20 & 0.97 & 1.60 & 4.93 & 0.92 \\
Complexity rating & 2.62 & 2.64 & 0.83 & 1.04 & 4.60 & 0.16 \\
Familiarity & 2.97 & 3.01 & 0.92 & 1.38 & 4.95 & 0.16 \\
Meaningfulness & 2.80 & 2.80 & 0.94 & 1.28 & 4.75 & 0.04 \\
Semantic distance & 2.59 & 2.52 & 0.98 & 1.02 & 4.90 & 0.52 \\
Complexity metric & 8.60 & 6.00 & 8.28 & 1.00 & 51.00 & 2.23 \\
Concept agreement (\%) & 15.49 & 2.50 & 22.39 & 0.00 & 82.50 & 1.47 \\
Name agreement (\%) & 31.39 & 25.00 & 23.04 & 2.50 & 87.50 & 0.56 \\
\hline
\end{tabular}

metaphor along with the simplicity principle is likely to produce particularly effective symbols.

Other correlations. Other interrelationships between symbol characteristics are shown in Table 2. Although concreteness did not correlate with visual complexity, it was found to be closely related to meaningfulness. These findings provide support for the suggestion made by Y. Rogers and others that concrete symbols tend to be more meaningful than abstract symbols. This is probably because use of familiar real-world objects in concrete symbols allows the user to ascertain their meaning even when they are encountered for the first time. Abstract symbols, in contrast, are only likely to become meaningful when users learn the symbol-function relationship. As can be seen from the Appendix, the few items that were meaningful but not concrete tended to be ones with which users were familiar (e.g., symbols denoting female and male genders, Items 93 and 143; symbols denoting eject and fast-forward functions on a video recorder, Items 74 and 91). We would therefore predict that the relationship between concreteness and meaningfulness would diminish as symbol-function relationships are learned. This notion is supported by previous research showing that the effects of symbol concreteness on performance diminish over learning trials (Arend et al., 1987; Stammers et al., 1989).

In the context of this study, meaningfulness and familiarity appear to be virtually interchangeable $\left(r_{\mathrm{s}}=.93\right)$. For familiar items, participants could readily access a meaning, even though it might not be correct, by drawing on their real-world experiences. For example, Item 176 in the Appendix is used to denote portable file. In order to access meaning for this symbol, most participants used a picture-labeling strategy and stated that it was a sign for luggage storage. Thus the symbol appeared meaningful and familiar while, at the same time, most participants were ignorant of its function. In these cases, the most popular name for the symbol did not match the given function name. Where items were not familiar, access to meaning was much more difficult. For example, Item 126 shows a jacketed reactor, an item unfamiliar to most individuals. This makes it difficult to adopt the labeling strategy used for other, more familiar, symbols.

Further support for the notion that participants often adopted a labeling strategy in order to access meaning comes from the pattern of correlations shown in Table 2 for concept agreement and name agreement. Concept agreement measures the percentage of participants who were able to give the appropriate function name, or meaning, for the symbol. In contrast, name agreement is a measure of the percentage of participants giving the most common meaning, irrespective of whether it was correct or not. The concept agreement rating was most closely related to the semantic distance rating. This seems likely to be because in rating semantic distance, participants were given the function label. Correlations of concept agreement with familiarity and meaningfulness ratings, where the function label was not provided, were lower. This sit- 
Table 2

Correlations Between Symbol Characteristics

\begin{tabular}{lcccccccc}
\hline \multicolumn{1}{c}{ Measure } & Conc & $\begin{array}{c}\text { Comp } \\
\text { Rating }\end{array}$ & $\begin{array}{c}\text { Comp } \\
\text { Metric }\end{array}$ & Fam & Mean & SemD & $\begin{array}{c}\text { Con } \\
\text { Agree }\end{array} \begin{array}{c}\text { Name } \\
\text { Agree }\end{array}$ \\
\hline Concreteness & 1.00 & & & & & & & \\
Complexity rating & $n . s$. & 1.00 & & & & & & \\
Complexity metric & $n . s$. & .73 & 1.00 & & & & & \\
Familiarity & .78 & -.31 & -.27 & 1.00 & & & & \\
Meaningfulness & .82 & -.25 & -.19 & .93 & 1.00 & & & \\
Semantic distance & .65 & $n . s$. & $n . s$. & .55 & .61 & 1.00 & & \\
Concept agreement & .41 & -.17 & $n . s$. & .51 & .51 & .69 & 1.00 & \\
Name agreement & .46 & -.22 & $n . s$. & .79 & .86 & .54 & .46 & 1.00 \\
\hline
\end{tabular}

Note-Conc, concreteness; Comp Rating, complexity rating; Comp Metric, complexity metric; Fam, familiarity; Mean, meaningfulness; SemD, semantic distance; Con Agree, concept agreement; Name Agree, name agreement.

uation was reversed for name agreement. Correlations were highest with meaningfulness and familiarity, since items for which a labeling strategy were used were incorporated within the measurement of name agreement.

\section{CONCLUSIONS}

There has been a long tradition in psycholinguistic research of using normative ratings to manipulate or control variables in the course of experimentation (e.g., Gilhooly \& Logie, 1980; Martein, 1995; Paivio et al., 1968; Sanfeliu \& Fernandez, 1996; Snodgrass \& Vanderwart, 1980). This means that research concerning the processing of pictures and words can be carried out after potential artifacts have been eliminated. In contrast, research examining the effects of symbol characteristics on user performance is a relatively recent undertaking and, as a result, researchers have been forced to rely on creating their own, sometimes idiosyncratic, symbol stimuli. This paper used the ratings methodology to quantify the characteristics of a broad range of symbols that may be used as experimental stimuli. The dimensions for which ratings were obtained are correlates of symbol usability given prominence in previous research. The importance of appropriate experimental control was evident when the relationship between concreteness and visual complexity was investigated. In general, with the exception of measures of visual complexity, relationships between ratings were close. In particular, strong correlations were apparent between concreteness, meaningfulness, and familiarity. However, there is some evidence to suggest that these relationships may break down as users learn symbol-function relationships. In this way, symbols differ from words where relationships between word characteristics are much more stable. This is because the relationship between written words (the symbol) and what they refer to is already known.

\section{REFERENCES}

American Institute of Graphic Arts (1982). Symbol signs. New York: Hastings House.

Arend, U., Muthig, K.-P.. \& Wandmacher, J. (1987). Evidence for global feature superiority in menu selection by icons. Behaviour \& Information Technology, 6, 411-426.

ARNSTEIN, J. (1983). The international directory of graphic symbols. London: Kogan Page.

Benjafield, J., Frommhold, K., Keenan, T., Muckenheim, R., \& Mueller, D. (1993). Imagery, concreteness, goodness, and familiarity ratings for 500 proverbs sampled from the Oxford Dictionary of English Proverbs. Behavior Research Methods, Instruments, \& Computers, 25, 27-40.

Benjafield, J., \& Muckenheim, R. (1989). Dates of entry and measures of imagery, concreteness, goodness, and familiarity for 1,046 words sampled from the Oxford English Dictionary. Behavior Research Methods, Instruments, \& Computers, 21, 31-52.

Blattner, M. M., Sumikawa, D. A., \& Greenberg, R. M. (1989). Earcons and icons: Their structure and common design principles. Human-Computer Interaction, 4, 11-44.

BOCKer, M. (1993, May). A multiple index approach for the evaluation of pictograms. Proceedings of the Fourteenth International Symposium of Human Factors in Telecommunication (pp. 73-84). Heidelberg: R v Deckers Verlag, G. Schenck GmBH.

Brems, D. J., \& Whitten, W. B. (1987). Learning and preference for icon-based interface. In Proceedings of the Human Factors Society Thirty-first Annual Meeting (pp. 125-129). Santa Monica, CA: Human Factors Society.

BRITISH STANDARDS INSTITUTION (1989). 5817-8 specification for audio-visual, video and television equipment and systems. London: BSI

BYRNE, M. D. (1993). Using icons to find documents: Simplicity is critical. In S. Ashlund, K. Mullet, A. Henderson, E. Hollnagel, \& T. White (Eds.), INTERCHI 93 - Bridges between worlds: Proceedings of the Conference on Human Factors in Computing Systems (pp. 446-453). Reading, MA: Addison-Wesley.

CAHILL, M. (1975). The interpretability of graphic symbols as a function of context and experience factors. Journal of Applied Psychology, 60, 360-380.

Christ, R. E., \& Corso, G. (1982). The effects of extended practice on the evaluation of visual display codes. Human Factors, 25, $71-84$.

Deaton, J. E., Barnes, M., KerN, J., \& Wright, D. (1990). An evaluation of the augie arrow HUD symbology as an aid to recovery from unusual attitudes. In Proceedings of the Human Factors Society Thirty-Fourth Annual Meeting (pp. 31-35). Santa Monica, CA: Human Factors Society.

Easterby, R. S. (1970). The perception of symbols for machine displays. Ergonomics, 13, 149-158.

Ells, J. G., \& Dewar, R. E. (1979). Rapid comprehension of verbal and symbolic traffic sign messages. Human Factors, 21, 161-168.

Familant, E. M., \& Detweiler, M. C. (1993). Iconic reference: Evolving perspectives and an organising framework. International Journal of Man-Machine Studies, 39, 705-728.

FLACH, J. M., \& VICENTE, K. J. (1989). Complexity, difficulty, direct manipulation and direct perception (Tech. Rep. EPRL-89-03). Urbana- 
Champaign: University of Illinois, Engineering Psychology Research Laboratory.

Friendly, M., Frankein, P. E., Hoffman, D. \& Rubin, D. C. (1982). The Toronto Word Pool: Norms for imagery, concreteness, orthographic variables, and grammatical usage for 1,080 words. Behavior Research Methods \& Instrumentation, 14, 375-399.

Garcia, M., Badre, A. N., \& Stasko, J. T. (1994). Development and validation of icons varying in their abstractness. Interacting with Computers, 6, 191-211.

GiLhooly, K. J., \& Logie, R. H. (1980). Age-of-acquisition, imagery, concreteness, familiarity, and ambiguity measures for 1,944 words. Behavior Research Methods \& Instrumentation, 12, 395-427.

GiTTINS, D. (1986). Icon-based human-computer interaction. International Journal of Man-Machine Studies, 24, 519-543.

Green, A. J. K., \& BarNarD, P. J. (1990). Iconic interfacing: The role of icon distinctiveness and fixed or variable screen locations. In D. Diaper et al. (Eds.), Human-computer interaction-Interact' 90 (pp. 457-462). Amsterdam: Elsevier.

GrEeN, P. (1993). Design and evaluation of symbols for automobile controls and displays. In B. Peacock \& W. Karwowski (Eds.), Automotive ergonomics (pp. 237-268). Washington, DC: Taylor \& Francis.

Hartshorne, D. Weiss, P., \& BURKs, A. (Eds.) (1958). The collected papers of Charles Sanders Peirce. Cambridge, MA: Harvard University Press.

HORTON, W. (1994). The icon book: Visual symbols for computer systems and documentation. New York: Wiley.

Howell, W. E. \& FuCHS, A. F. (1968). Population stereotype in code design. Organisational Behavior \& Human Performance, 3, 310-339.

International EleCtrotechnical Commission (1973). IEC 417. Graphical symbols for use on equipment. Geneva: Author.

InTERnational Standards Organisation (1982). Benefits of standardisation: Methods of assessing the effects of standardisation. Geneva: Author.

INTERNATIONAL STANDARDS ORGANISATION (1989). ISO 7000: Graphical symbols for use on equipment -Index and synopsis. Geneva: Author.

INTERNATIONAL Standards ORganisation (1990). ISO 7001: Specification for public information symbols. Geneva: Author.

InTERnational STANDaRds ORGanisation (1994). ISO brochure. Compatible technology world-wide. Geneva: Author.

INTERNATIONAL STANDARDS ORGANISATION (1995). ISO 2575: Road vehicles-Symbols for controls, indicators and tell-tales. Geneva: Author.

JONES, S. (1983). Stereotypy in pictograms of abstract concepts. Ergonomics, 26, 605-611.

KirkPatrick, M., Dutra, L. A., Lyons, R. A., Osga, G. A., \& Pucci, J. J. (1992). Tactical symbology standards. In Proceedings of the Human Factors Society Thirty-Sixth Annual Meeting (pp. 1087. 1091). Santa Monica, CA: Human Factors Society.

Lachman, R., \& LaChman, J. L. (1980). Picture naming: Retrieval and activation of long-term memory. In L. W. Poon, J. L. Fozard, L. S. Cermak, D. Arenberg, \& L. W. Thompson (Eds.), New directions in memory and ageing (pp. 313-343). Hillsdale, NJ: Erlbaum.

Margono, S., \& Shneiderman, B. (1987). A study of file manipulation by novices using commands vs direct manipulation. In B. Shneiderman (Ed.), Sparks of innovation in the human-computer interface (pp. 39-50). Norwood, NJ: Ablex.

MARTEIN, R. (1995). Norms for name and concept agreement, familiarity, visual complexity and image agreement on a set of 216 pictures. Psychologica Belgica, 35, 205-225.

McDougall, S. J. P., Curry, M., \& de Bruijn, O. (1996). A review of symbol characteristics and their effects on usability (Document D1, British Aerospace Effective Symbology Project).

Microsoft Corporation (1989). Microsoft Access 2.0. Redmond, WA: Author.

Microsoft Corporation (1995). Microsoft Word for Windows '95. Version 7. Redmond, WA: Author.

MOYES, J., \& JORDAN, P. W. (1993). Icon design and its effect on guessability, learnability and experienced user performance. In J. L. Alty,
D. Diaper, \& S. Guest (Eds.), People and computers VIII (pp. 49-59). Cambridge: Cambridge University Press.

Muter, P., \& Marson, C. (1986). The role of graphics in item selection from menus. Behaviour \& Information Technology, 5, 89-95.

North Atlantic Treaty Organization (1989). STaNAG 4420: Display symbology and colors for NATO maritime units. Brussels: Author.

Paivio, A., Yuille, J. C., \& Madigan, S. A. (1968). Concreteness, imagery, and meaningfulness values for 925 nouns. Journal of Experimental Psychology Monograph Supplement, 76, 1-25.

QUinLAN, P. (1992). The MRC psycholinguistic database. Cambridge: Cambridge University Press.

ROGERS, Y. (1986). Evaluating the meaningfulness of icon sets to represent command operations. In M. D. Harrison \& A. F. Monk (Eds.), People and computers: Designing for usability (pp. 586-603). Cambridge: Cambridge University Press.

ROGERS, Y. (1988). Pictorial representations of abstract concepts in relation to human computer interaction. Unpublished doctoral dissertation thesis, University of Wales Swansea.

ROGERS, Y. (1989). Icon design for the user interface. International Review of Ergonomics, 2, 129-154.

Rogers, Y., \& OBORNE, D. J. (1987). Pictorial communication of abstract verbs in relation to human-computer interaction. British Journal of Psychology, 78, 99-112.

ROHR, G., \& KEPPEL, E. (1985), lconic interfaces: Where to use and how to construct. In H. W. Hendrick \& O. Brown (Eds.), Human factors in organization design and management (pp. 269-275). Amsterdam: Elsevier.

Sanfeliu, M. C., \& Fernandez, A. (1996). A set of 254 SnodgrassVanderwart pictures standardized for Spanish: Norms for name agreement, image agreement, familiarity, and visual complexity. Behavior Research Methods, Instruments, \& Computers, 28, 537-555.

Snodgrass, J. G., \& Vanderwart, M. (1980). A standardized set of 260 pictures: Norms for name agreement, image agreement, familiarity and visual complexity. Journal of Experimental Psychology: Human Learning \& Memory, 6, 174-215.

SNodgrass, J. G., \& Yuditsky, T. (1996). Naming times for the Snodgrass and Vanderwart pictures. Behavior Research Methods, Instruments, \& Computers, 28, 516-536.

SPReen, O., \& Schulz, R. W. (1966). Parameters of abstraction, meaningfulness, and pronounceability for 329 nouns. Journal of Verbal Learning \& Verbal Behavior, 5, 459-468.

Stammers, R. B., George, D. A., \& Carey, M. S. (1989). An evaluation of abstract and concrete icons for a CAD package. In E. D. Megaw (Ed.), Contemporary ergonomics 1989 (pp. 416-421). London: Taylor \& Francis

Stammers, R. B., \& Hoffman, J. (1991). Transfer between icon sets and ratings of icon concreteness and appropriateness. In Proceedings of the Human Factors Society Thirty-Fifth Annual Meeting (pp. 354358). Santa Monica, CA: Human Factors Society.

Toglia, M. P., \& BatTig W. F. (1978). Handbook of semantic word norms. Hillsdale, NJ: Erlbaum.

TuLLIS, T. S. (1983). The formatting of alphanumeric displays: A review and analysis. Human Factors, 25, 657-682.

van Schagen, I., Tamsma, N., Bruggemann, F., Jackson, J. L. \& MiCHON, J. A. (1983). Namen en normen voor plaatje [Names and norms for pictures]. Nederlands Tijdschrift voor de Psychologie, 38, 236241.

$\mathrm{W}_{3} \mathrm{C}$ (1996). HTML predefined icon-like symbols [On-line]. Available HTML: http//www.w3.org/pub/www/tr/wd-wwwicn

ZWAGA, H., \& EASTERBY, R. (1984). Developing effective symbols for public information. In R. Easterby \& H. Zwaga (Eds.), Information design: The design and evaluation of signs and printed material (pp. 277-298). New York: Wiley

\section{NOTE}

1. Unless otherwise specified, the term symbot refers to icons, pictograms, symbols, and signs. 
APPENDIX

Symbols and Ratings Listed in Alphabetical Order

1 Add task

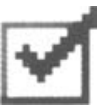

3 Adjust contrast

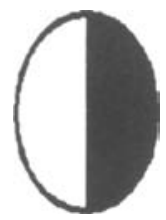

5 Air vent - right and left outlets
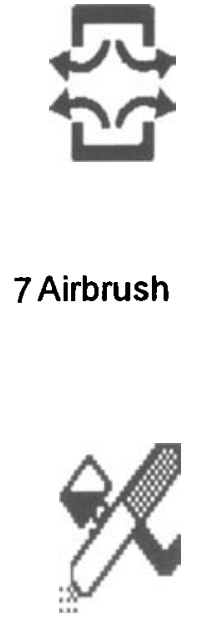

$\begin{array}{lr}\text { Concreteness: } & 2.47 \\ \text { Complexity: } & 2.55 \\ \text { Familiarity: } & 3.05 \\ \text { Meaningfulness: } & 3.45 \\ \text { Semantic Distance: } & 2.03 \\ \text { Complexity Metric: } & 2 \\ \text { Concept Agreement: } & 0.00 \\ \text { Name Agreement: } & 42.50 \\ & \text { correct }\end{array}$

Concreteness:

Familiarity:

Meaningfulness:

Semantic Distance:

Complexity Metric:

Concept Agreement:

Name Agreement: colour

$\begin{array}{lr}\text { Concreteness: } & 1.98 \\ \text { Complexity: } & 2.60 \\ \text { Familiarity: } & 2.05 \\ \text { Meaningfulness: } & 2.10 \\ \text { Semantic Distance: } & 2.57 \\ \text { Complexity Metric: } & 10 \\ \text { Concept Agreement: } & 7.50 \\ \text { Name Agreement: } & 15.00 \\ & \text { exits }\end{array}$

$\begin{array}{lr}\text { Concreteness: } & 2.22 \\ \text { Complexity: } & 3.90 \\ \text { Familiarity: } & 1.55 \\ \text { Meaningfulness: } & 1.60 \\ \text { Semantic Distance: } & 2.24 \\ \text { Complexity Metric: } & 16 \\ \text { Concept Agreement: } & 7.50 \\ \text { Name Agreement: } & 7.50\end{array}$

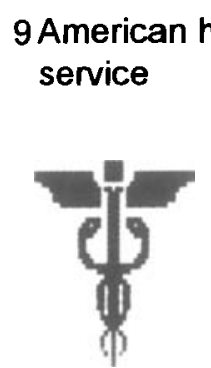

$\begin{array}{lr}\text { Concreteness: } & 2.70 \\ \text { Complexity: } & 3.97 \\ \text { Familiarity: } & 2.70 \\ \text { Meaningfulness: } & 2.28 \\ \text { Semantic Distance: } & 1.60 \\ \text { Complexity Metric: } & 6 \\ \text { Concept Agreement: } & 0.00 \\ \text { Name Agreement: } & 10.00 \\ & \text { medical }\end{array}$
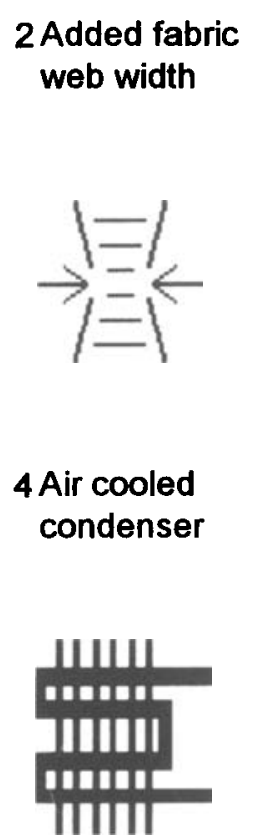

$\begin{array}{lr}\text { Concreteness: } & 2.27 \\ \text { Complexity: } & 2.80 \\ \text { Familiarity: } & 1.93 \\ \text { Meaningfulness: } & 1.98 \\ \text { Semantic Distance: } & 1.89 \\ \text { Complexity Metric: } & 14 \\ \text { Concept Agreement: } & 0.00 \\ \text { Name Agreement: } \quad 7.50 \\ & \text { narrowing }\end{array}$

$\begin{array}{lr}\text { Concreteness: } & 1.85 \\ \text { Complexity: } & 3.50 \\ \text { Familiarity: } & 1.75 \\ \text { Meaningfulness: } & 1.33 \\ \text { Semantic Distance: } & 1.56 \\ \text { Complexity Metric: } & 7 \\ \text { Concept Agreement: } & 0.00 \\ \text { Name Agreement: } & 5.00 \\ & \text { magnet }\end{array}$

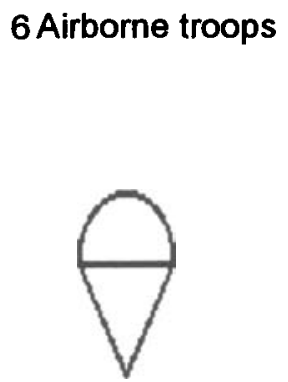

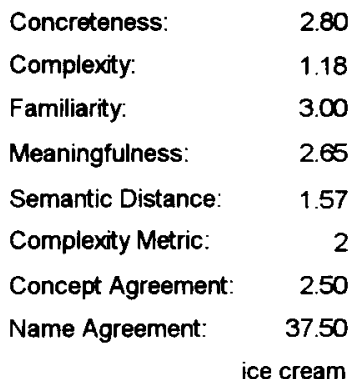

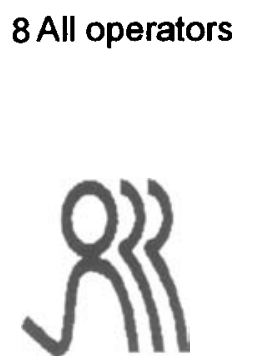

Concreteness:

2.80

Complexity:

2.10

Familiarity:

2.50

Meaningfulness:

2.32

Semantic Distance:

1.74

Complexity Metric:

Concept Agreement:

4

Name Agreement:

17.50

people

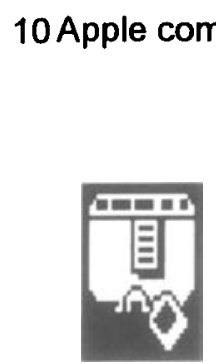

Concreteness:

2.93

Complexity:

4.13

Familiarity:

1.98

Meaningfulness:

1.70

Semantic Distance: $\quad 1.64$

Complexity Metric: $\quad 14$

Concept Agreement: $\quad 5.00$

Name Agreement: $\quad 5.00$ 


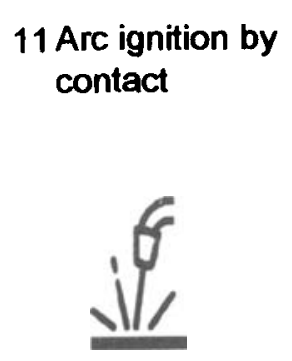

$\begin{array}{lr}\text { Concreteness: } & 3.13 \\ \text { Complexity: } & 2.37 \\ \text { Familiarity: } & 2.65 \\ \text { Meaningfulness: } & 2.35 \\ \text { Semantic Distance: } & 1.68 \\ \text { Complexty Metric: } & 8 \\ \text { Concept Agreement: } & 0.00 \\ \text { Name Agreement: } & 20.00 \\ & \text { tap }\end{array}$

12Archive

Concreteness:

2.15

Complexity: $\quad 3.47$

85

Familiarity:

1.96

Meaningfulness: $\quad 1.50$

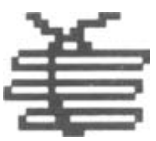

Semantic Distance: $\quad 1.50$

Complexity Metric: $\quad 7$

Concept Agreement: $\quad 0.00$

Name Agreement: $\quad 5.00$

bundle of wood

13 Atomic site

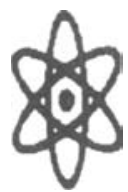

15 Axe

17 Balance

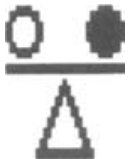

19 Belt drive

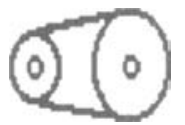

Concreteness: $\quad 3.18$

Complexity: $\quad 2.53$

Familiarity:

3.73

Meaningfulness:

2.78

Semantic Distance: $\quad 2.31$

Complexity Metric: 4

Concept Agreement: $\quad 2.50$

Name Agreement: $\quad 20.00$

atom

Concreteness: $\quad 3.85$

Complexity: $\quad 1.25$

Familiarity: $\quad 3.12$

Meaningfulness: $\quad 3.30$

Semantic Distance: $\quad 3.95$

Complexity Metric: $\quad 2$

Concept Agreement: $\quad 40.00$

Name Agreement: $\quad 40.00$

Concreteness: $\quad 2.50$

Complexity: $\quad 2.38$

Familiarity: $\quad 2.60$

Meaningfulness: $\quad 3.17$

Semantic Distance: $\quad 3.86$

Complexity Metric: $\quad 4$

Concept Agreement: $\quad 37.50$

Name Agreernent: $\quad 37.50$

$\begin{array}{lr}\text { Concreteness: } & 3.38 \\ \text { Complexity: } & 1.68 \\ \text { Familiarity: } & 3.10 \\ \text { Meaningfulness: } & 2.51 \\ \text { Semantic Distance: } & 2.90 \\ \text { Complexity Metric: } & 6 \\ \text { Concept Agreement: } & 0.00 \\ \text { Name Agreement: } & 57.50 \\ & \text { pulley }\end{array}$

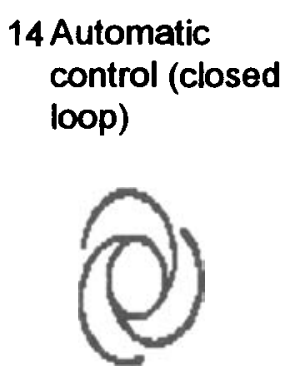

Concreteness: $\quad 1.85$

Complexity: $\quad 2.73$

Familiarity: $\quad 1.93$

Meaningfulness: $\quad 1.68$

Semantic Distance: $\quad 1.39$

Complexity Metric: $\quad 4$

Concept Agreement: $\quad 0.00$

Name Agreement: $\quad 10.00$

spinning
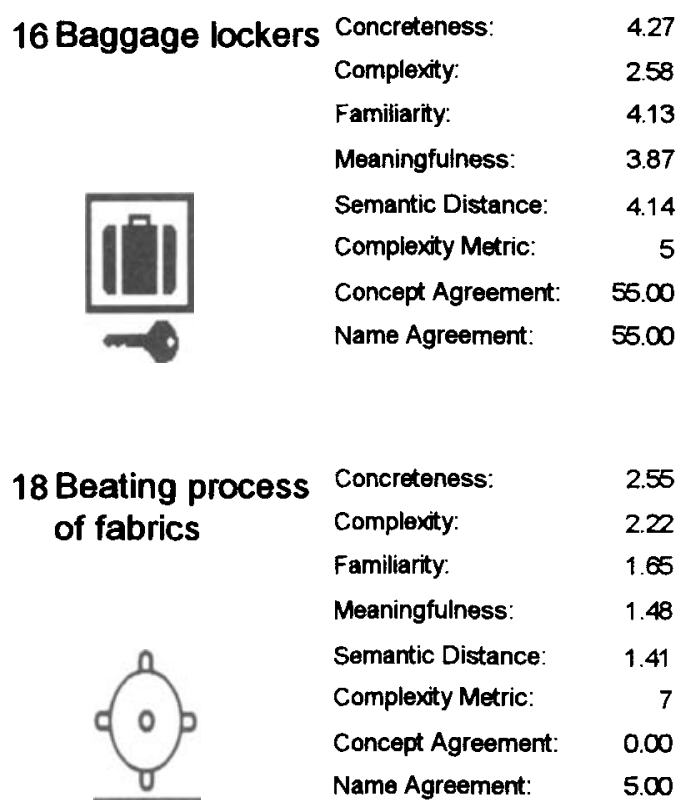

$\begin{array}{lr}\text { Concreteness: } & 2.55 \\ \text { Complexity: } & 2.22 \\ \text { Familiarity: } & 1.65 \\ \text { Meaningfulness: } & 1.48 \\ \text { Semantic Distance: } & 1.41 \\ \text { Complexty Metric: } & 7 \\ \text { Concept Agreement: } & 0.00 \\ \text { Name Agreement: } & 5.00\end{array}$

20 Bending

Concreteness: $\quad 2.00$

Complexity: $\quad 3.40$

Familiarity: $\quad 1.65$

Meaningfulness: $\quad 1.35$

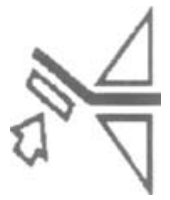

Semantic Distance:

2.74

Complexity Metric:

5

Concept Agreement: $\quad 2.50$

Name Agreement: $\quad 2.50$ 
APPENDIX (Continued)

\begin{tabular}{|c|c|c|c|c|c|}
\hline \multirow{4}{*}{21 Binary file } & Concreteness: & 1.80 & \multirow{3}{*}{22 Biohazard } & Concreteness: & 1.85 \\
\hline & Complexity: & 3.88 & & Complexity: & 3.65 \\
\hline & Familiarity: & 2.45 & & Familiarity: & 2.45 \\
\hline & Meaningfulness: & 2.28 & & Meaningfulness: & 1.85 \\
\hline |이미|잉 & Semantic Distance: & 2.88 & & Semantic Distance: & 1.48 \\
\hline 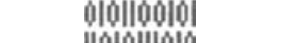 & Complexity Metric: & 51 & & Complexity Metric: & 6 \\
\hline 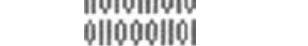 & Concept Agreement: & 20.00 & & Concept Agreement: & 5.00 \\
\hline 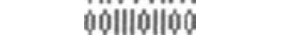 & Name Agreement: & 20.00 & & Name Agreement: & 5.00 \\
\hline \multirow{9}{*}{23 Bitmap } & Concreteness: & 2.33 & \multirow{9}{*}{24 Blow moulding } & Concreteness: & 4.65 \\
\hline & Complexity: & 2.93 & & Complexity: & 1.13 \\
\hline & Familiarity: & 2.27 & & Familiarity: & 4.33 \\
\hline & Meaningfuiness: & 1.68 & & Meaningfulness: & 3.88 \\
\hline & Semantic Distance: & 1.85 & & Semantic Distance: & 1.35 \\
\hline & Complexity Metric: & 12 & & Complexity Metric: & 1 \\
\hline & Concept Agreement: & 0.00 & & Concept Agreement: & 0.00 \\
\hline & Name Agreement: & 17.50 & & Name Agreement: & 60.00 \\
\hline & & game & & & bottle \\
\hline \multirow{9}{*}{$\begin{array}{l}25 \text { Break glass to } \\
\text { access }\end{array}$} & Concreteness: & 3.63 & \multirow[t]{9}{*}{26 Bridging troops } & Concreteness: & 2.12 \\
\hline & Complexity: & 3.20 & & Complexity: & 1.65 \\
\hline & Familiarity: & 3.02 & & Familiarity. & 2.87 \\
\hline & Meaningfulness: & 2.80 & & Meaningfulness: & 2.13 \\
\hline & Semantic Distance: & 3.31 & & Semantic Distance: & 1.61 \\
\hline & Complexity Metric: & 5 & & Complexity Metric: & 2 \\
\hline & Concept Agreement: & 7.50 & & Concept Agreement: & 27.50 \\
\hline & Name Agreement: & 15.00 & & Name Agreement: & 27.50 \\
\hline & & rolution & & & \\
\hline \multirow{9}{*}{$\begin{array}{l}27 \text { Brushing by } \\
\text { means of brush } \\
\text { belt }\end{array}$} & Concreteness: & 3.03 & \multirow{9}{*}{ 28Building } & Concreteness: & 4.70 \\
\hline & Complexity: & 2.20 & & Complexity: & 3.88 \\
\hline & Familiarity: & 2.20 & & Familiarity: & 3.88 \\
\hline & Meaningfulness: & 1.96 & & Meaningfulness: & 3.53 \\
\hline & Semantic Distance: & 1.98 & & Semantic Distance: & 4.67 \\
\hline & Complexity Metric: & 14 & & Complexity Metric: & 11 \\
\hline & Concept Agreement: & 0.00 & & Concept Agreement: & 70.00 \\
\hline & Name Agreement: & 12.50 & & Name Agreement: & 70.00 \\
\hline & & $\operatorname{cog}$ & & & \\
\hline \multirow[t]{8}{*}{29 Button } & Concreteness: & 2.53 & \multirow[t]{8}{*}{30 Calendar } & Concreteness: & 4.30 \\
\hline & Complexity: & 2.73 & & Complexity: & 3.15 \\
\hline & Familiarity: & 2.50 & & Familiarity: & 3.22 \\
\hline & Meaningfulness: & 1.95 & & Meaningfuiness: & 2.90 \\
\hline & Semantic Distance: & 2.74 & & Semantic Distance: & 3.45 \\
\hline & Complexity Metric: & 2 & & Complexity Metric: & \\
\hline & Concept Agreement: & 17.50 & & Concept Agreement: & 22.50 \\
\hline & Name Agreement: & 17.50 & & Name Agreement: & 22.50 \\
\hline
\end{tabular}




$\begin{array}{lll}31 \text { Cancer } & \text { Concreteness: } & 4.52 \\ & \text { Complexity: } & 3.4 \\ & \text { Familiarity: } & 3.23 \\ & \text { Meaningfulness: } & 3.73 \\ & \text { Semantic Distance: } & 250 \\ \text { Complexity Metric: } & \text { Concept Agreement: } & 12.50 \\ & \text { Name Agreement: } & \end{array}$

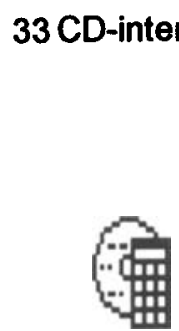

$\begin{array}{lr}\text { Concreteness: } & 2.35 \\ \text { Complexity. } & 3.35 \\ \text { Familiarity. } & 1.82 \\ \text { Meaningfulness: } & 1.90 \\ \text { Semantic Distance: } & 2.00 \\ \text { Complexity Metric: } & 17 \\ \text { Concept Agreement: } & 0.00 \\ \text { Name Agreement: } & 17.50\end{array}$

$C D$

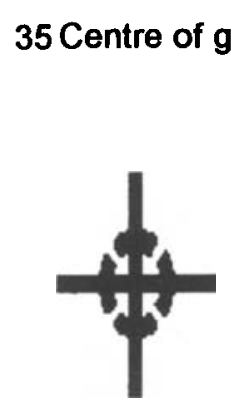

37 Chain saw

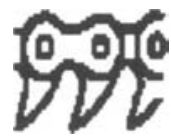

39 Chess

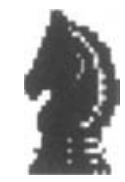

$\begin{array}{lr}\text { Concreteness: } & 4.60 \\ \text { Complexity: } & 3.43 \\ \text { Familiarity: } & 4.45 \\ \text { Meaningfulness: } & 4.18 \\ \text { Semantic Distance: } & 4.38 \\ \text { Complexity Metric: } & 8 \\ \text { Concept Agreement: } & 82.50 \\ \text { Name Agreement: } & 82.50\end{array}$

2.35

3.35

1.82

1.90

200

4.40

2.55

1.78

2.43

1.76

Semantic Distance:

Complexity Metric:

Concept Agreement:

Name Agreement:

15.00

target

Concreteness:

Complexity:

3.48

Familiarity:

2.47

2.95

Meaningfulness: $\quad 3.03$

Semantic Distance: $\quad 3.05$

Complexity Metric: $\quad 10$

Concept Agreement: $\quad \mathbf{4 2 . 5 0}$

Name Agreement: $\quad \mathbf{4 2 5 0}$

Name Agreement:

4.60

3.43

4.45

4.18

438

8

82.50

APPENDIX (Continued)

4.52

3.42

3.23

3.73

2.50

13

12.50

crab
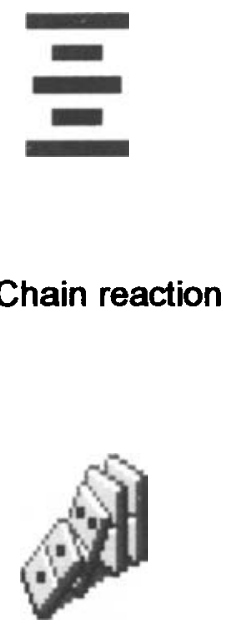

36 Chain reaction

32 Cartoons

34 Centre
alignment

38 Chemistry

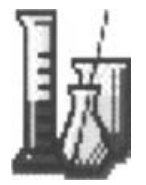

Concreteness:

3.83

Complexity

3.70

Familiarity:

2.43

Meaningfulness: $\quad 2.73$

Semantic Distance: $\quad 2.10$

Complexity Metric: $\quad 11$

Concept Agreement: $\quad 0.00$

Name Agreement: $\quad 20.00$

man

Concreteness: $\quad 1.85$

Complexity: $\quad 1.90$

Familiarity: $\quad 2.05$

Meaningfuiness: $\quad 1.70$

Semantic Distance: $\quad 2.52$

Complexity Metric: $\quad 5$

Concept Agreement: $\quad 0.00$

Name Agreement: $\quad 5.00$

battery

Concreteness: $\quad 4.72$

Complexity: $\quad 3.38$

Familiarity: $\quad 3.58$

Meaningfulness: $\quad 3.58$

Semantic Distance: $\quad 3.00$

Complexity Metric: $\quad 8$

Concept Agreement: $\quad 10.00$

Name Agreement: $\quad 67.50$

dominoes

Concreteness: $\quad 4.83$

Complexity: $\quad 3.25$

Familiarity: $\quad 4.10$

Meaningfulness: $\quad 3.78$

Semantic Distance: $\quad 3.90$

Complexity Metric: $\quad 12$

Concept Agreement: $\quad \mathbf{4 0 . 0 0}$

Name Agreement: $\quad 40.00$

Concreteness: $\quad 2.40$

Complexity: $\quad 1.80$

Familiarity: $\quad 3.20$

Meaningfulness: $\quad 2.35$

Semantic Distance: $\quad 1.90$

Complexity Metric: $\quad 4$

Concept Agreement: $\quad 15.00$

Name Agreement: $\quad 15.00$ 
APPENDIX (Continued)

$\begin{array}{llr}\text { 41. Christianity } & \text { Concreteness: } & 4.50 \\ & \text { Complexity: } & 3.95 \\ & \text { Familiarity: } & 4.10 \\ & \text { Meaningfulness: } & 4.10 \\ & \text { Semantic Distance: } & 3.71 \\ & \text { Complexity Metric: } & 10 \\ & \text { Concept Agreement: } & 0.00 \\ & \text { Name Agreement: } & 67.50 \\ & & \text { Jesus }\end{array}$

\section{Cleaning of chain-link}

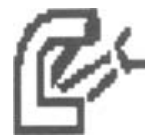

\section{Cockpit}
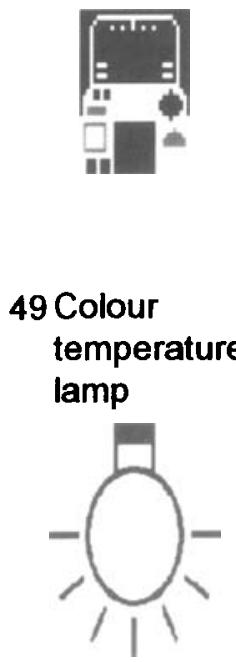

$\begin{array}{lr}\text { Concreteness: } & 2.28 \\ \text { Complexity: } & 2.87 \\ \text { Familiarity: } & 1.70 \\ \text { Meaningfulness: } & 1.57 \\ \text { Semantic Distance: } & 1.39 \\ \text { Complexity Metric: } & 6 \\ \text { Concept Agreement: } \quad 0.00 \\ \text { Name Agreement: } \quad 12.50 \\ \end{array}$

$\begin{array}{lr}\text { Concreteness: } & 1.85 \\ \text { Complexity: } & 2.38 \\ \text { Familiarity: } & 1.72 \\ \text { Meaningfulness: } & 1.68 \\ \text { Semantic Distance: } & 1.71 \\ \text { Complexity Metric: } & 5 \\ \text { Concept Agreement: } & 0.00 \\ \text { Name Agreement: } & 5.00\end{array}$

evaporation

Concreteness: $\quad 2.65$

Complexity: $\quad 4.60$

Familiarity: $\quad 1.73$

Meaningfulness: $\quad 1.65$

Semantic Distance: $\quad 2.55$

Complexity Metric: $\quad 26$

Concept Agreement: $\quad 0.00$

Name Agreement: $\quad 7.50$

computer

Concreteness: $\quad 3.80$

Complexity: $\quad 1.92$

Familiarity: $\quad 3.80$

Meaningfulness: $\quad 3.43$

Semantic Distance: $\quad 1.81$

Complexity Metric: $\quad 10$

Concept Agreement: $\quad 0.00$

Name Agreement: $\quad 40.00$

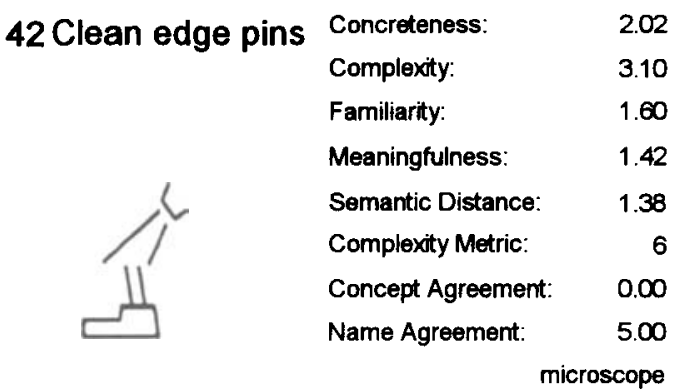

\section{Closed}

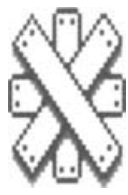

46 Co-operate

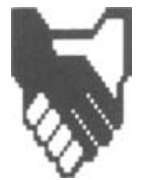

48 Colour area

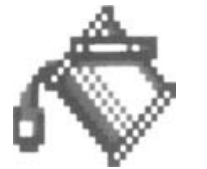

50 Communication

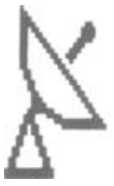

Concreteness:
Complexity:

4.30

Familiarity:

1.90

Familiarity:

Meaningfulness:

3.90

Semantic Distance:

Complexity Metric:

3.20

3.33

2.60

2.63

2.86

22

10.00

12.50

boarded up

\begin{tabular}{lr} 
Concreteness: & 4.35 \\
Complexity: & 2.90 \\
Familiarity: & 3.93 \\
Meaningfulness: & 4.10 \\
Semantic Distance: & 3.14 \\
Complexity Metric: & 6 \\
Concept Agreement: $\quad 0.00$ \\
Name Agreement: $\quad 22.50$ \\
\multicolumn{2}{r}{ racial equality }
\end{tabular}

52.50 
APPENDIX (Continued)

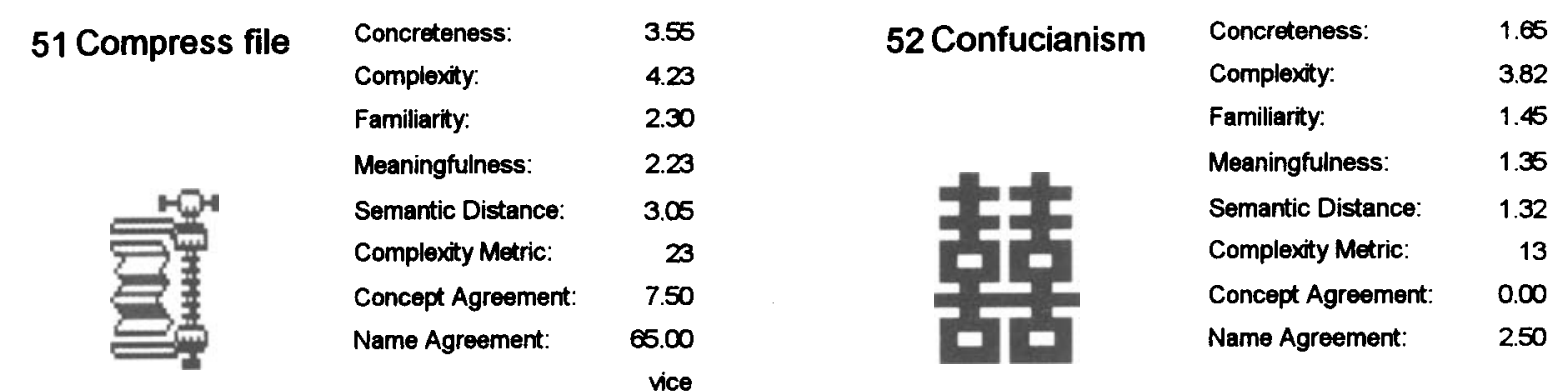

\section{Connect}
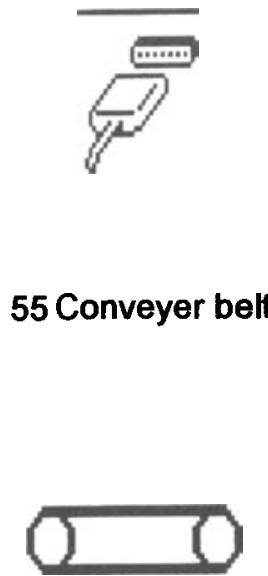

$\begin{array}{lr}\text { Concreteness: } & 4.35 \\ \text { Complexity: } & 2.90 \\ \text { Familiarity: } & 3.58 \\ \text { Meaningfulness: } & 3.56 \\ \text { Semantic Distance: } & 3.38 \\ \text { Complexty Metric: } & 11 \\ \text { Concept Agreement: } & 25.00 \\ \text { Name Agreement: } & \mathbf{2 5 . 0 0}\end{array}$

$\begin{array}{lr}\text { Concreteness: } & 2.65 \\ \text { Complexity: } & 1.40 \\ \text { Familiarity: } & 2.45 \\ \text { Meaningfulness: } & 2.18 \\ \text { Semantic Distance: } & 2.71 \\ \text { Complexity Metric: } & 4 \\ \text { Concept Agreement: } & 12.50 \\ \text { Name Agreement: } & 12.50\end{array}$

\section{Crop}

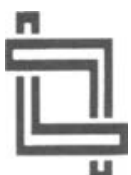

$\begin{array}{lr}\text { Concreteness: } & 1.67 \\ \text { Complexity: } & 2.50 \\ \text { Familiarity: } & 1.80 \\ \text { Meaningfulness: } & 1.38 \\ \text { Semantic Distance: } & 1.25 \\ \text { Complexity Metric: } & 4 \\ \text { Concept Agreement: } & 2.50 \\ \text { Name Agreement: } & 2.50\end{array}$

Concreteness:

Complexity.

Familiarity:

Meaningfulness:

Semantic Distance:

Complexity Metric:

Concept Agreement: Name Agreement:
4.40

2.08

3.87

3.90

3.07

8

10.00

70.00

money
54 Convert multiple files

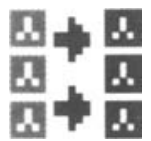

56 Creel

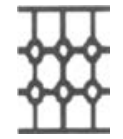

58 Cube

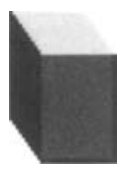

60 Dam

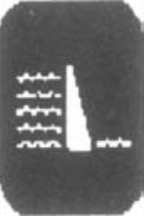

Concreteness: $\quad 1.92$

Complexity: $\quad 3.73$

Familiarity: $\quad 1.55$

Meaningfulness: $\quad 1.48$

Semantic Distance: $\quad 1.56$

Complexity Metric: $\quad 26$

Concept Agreement: $\quad 0.00$

Name Agreement: $\quad \mathbf{7 . 5 0}$

computer game

$\begin{array}{lr}\text { Concreteness: } & 1.95 \\ \text { Complexity: } & 2.75 \\ \text { Familiarity: } & 1.83 \\ \text { Meaningfulness: } & 1.73 \\ \text { Semantic Distance: } & 1.17 \\ \text { Complexity Metric: } & 25 \\ \text { Concept Agreement: } & 0.00 \\ \text { Name Agreement: } & 7.50 \\ & \text { molecules }\end{array}$

Concreteness: $\quad 4.20$

Complexity: $\quad 1.50$

Familiarity: $\quad 3.75$

Meaningtulness: $\quad 3.00$

Semantic Distance: $\quad 4.86$

Complexity Metric: $\quad 3$

Concept Agreement: $\quad 35.00$

Name Agreement: $\quad 35.00$

Concreteness: $\quad 3.03$

Complexity: $\quad 3.05$

Familiarity: $\quad 3.48$

Meaningfulness: $\quad 3.48$

Semantic Distance: $\quad 3.95$

Complexity Metric: 8

Concept Agreement: $\quad 22.50$

Name Agreement: $\quad 22.50$ 
APPENDIX (Continued)

\section{Dangerous voltage}

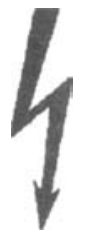

63 Debug

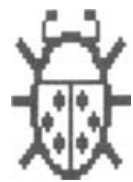

65 Device driver

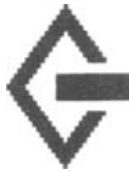

67 Diamond

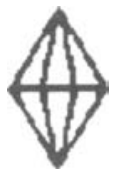

69 Distressed
vessel

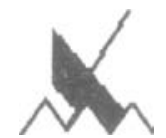

$\begin{array}{lr}\text { Concreteness: } & 3.93 \\ \text { Complexity: } & 1.23 \\ \text { Familiarity: } & 4.52 \\ \text { Meaningfulness: } & 4.18 \\ \text { Semantic Distance: } & 2.79 \\ \text { Complexity Metric: } & 1 \\ \text { Concept Agreement: } & 10.00 \\ \text { Name Agreement: } & 32.50 \\ & \text { lightning }\end{array}$

Concreteness: $\quad 4.33$

Complexity:

2.98

Familiarity:

3.20

Meaningfulness:

3.40

Semantic Distance:

Complexity Metric:

Concept Agreement:

Name Agreement:

30.00

ladybird

$\begin{array}{lr}\text { Concreteness: } & 1.82 \\ \text { Complexity: } & 2.18 \\ \text { Familiarity: } & 2.20 \\ \text { Meaningfulness: } & 1.28 \\ \text { Semantic Distance: } & 1.11 \\ \text { Complexity Metric: } & 2 \\ \text { Concept Agreement: } & 0.00 \\ \text { Name Agreement: } & 2.50\end{array}$

$\begin{array}{lr}\text { Concreteness: } & 2.68 \\ \text { Complexity: } & 2.28 \\ \text { Familiarity: } & 2.43 \\ \text { Meaningfulness: } & 2.88 \\ \text { Semantic Distance: } & 2.61 \\ \text { Complexity Metric: } & 6 \\ \text { Concept Agreement: } & 45.00 \\ \text { Name Agreement: } & 45.00\end{array}$

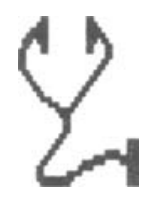

68 Discard files

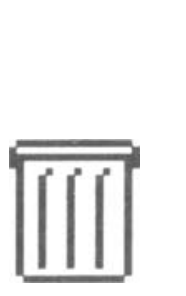

62 Debug

\section{Desk set}

66 Diagnose

70 Diver

Complexity:

3.45

2.35

Familiarity:

2.98

Meaningfulness

3.05

Semantic Distance:

Complexity Metric:

Concept Agreement: $\quad 0.00$

Name Agreement: $\quad 32.50$

$\begin{array}{lr}\text { Concreteness: } & 4.32 \\ \text { Complexity: } & 4.00 \\ \text { Familiarity: } & 3.20 \\ \text { Meaningfulness: } & 3.56 \\ \text { Sernantic Distance: } & 3.48 \\ \text { Complexity Metric: } r & 15 \\ \text { Concept Agreement: } \quad 2.50 \\ \text { Name Agreement: } \quad 45.00 \\ \end{array}$

Concreteness: $\quad 2.25$

Complexity: $\quad 4.25$

Familiarity: $\quad 1.80$

Meaningfulness: $\quad 1.60$

Semantic Distance: $\quad 1.95$

Complexity Metric: $\quad 40$

Concept Agreement: $\quad 0.00$

Name Agreement: $\quad 10.00$

computer

$\begin{array}{lr}\text { Concreteness: } & 4.47 \\ \text { Complexity: } & 2.05 \\ \text { Familiarity: } & 3.57 \\ \text { Meaningfulness: } & 3.47 \\ \text { Semantic Distance: } & 2.67 \\ \text { Complexity Metric: } & 1 \\ \text { Concept Agreement: } & 0.00 \\ \text { Name Agreement: } \quad 45.00 \\ \end{array}$

$\begin{array}{lr}\text { Concreteness: } & 3.78 \\ \text { Complexity: } & 1.95 \\ \text { Familiarity: } & 3.10 \\ \text { Meaningfulness: } & 3.58 \\ \text { Semantic Distance: } & 2.43 \\ \text { Complexity Metric: } & 5 \\ \text { Concept Agreement: } & 0.00 \\ \text { Name Agreement: } & 40.00 \\ & \text { dustbin }\end{array}$

\begin{tabular}{lr} 
Concreteness: & 2.15 \\
Complexity: & 2.38 \\
Familiarity: & 1.83 \\
Meaningfulness: & 1.45 \\
Semantic Distance: & 1.56 \\
Complexity Metric: & 5 \\
Concept Agreement: & 2.50 \\
Name Agreement: $\quad 5.00$ \\
\multicolumn{2}{l}{$\quad$ front of train }
\end{tabular}


APPENDIX (Continued)

$\begin{array}{llr}\text { 71 Draw } & \text { Concreteness: } & 3.25 \\ & \text { Complexity: } & 2.65 \\ & \text { Familiarity: } & 2.60 \\ & \text { Meaningfulness: } & 2.40 \\ & \text { Semantic Distance: } & 2.52 \\ & \text { Complexty Metric: } & 3 \\ & \text { Concept Agreement: } & 0.00 \\ & \text { Name Agreement: } & 20.00 \\ & & \text { fireworks }\end{array}$

73 Educate

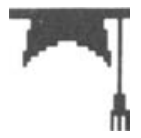

$\begin{array}{lr}\text { Concreteness: } & 3.75 \\ \text { Complexity: } & 2.25 \\ \text { Familiarity: } & 3.10 \\ \text { Meaningfulness: } & 3.33 \\ \text { Semantic Distance: } & 3.12 \\ \text { Complexity Metric: } r & 3 \\ \text { Concept Agreement: } \quad 10.00 \\ \text { Name Agreement: } \quad 30.00 \\ & \text { graduation }\end{array}$

Concreteness: $\quad 3.52$

Complexity:

Familiarity:

Meaningfulness:

2.55

3.35

Semantic Distance: $\quad 3.55$

Complexity Metric:

Concept Agreement:

Name Agreement:

57.50

shave

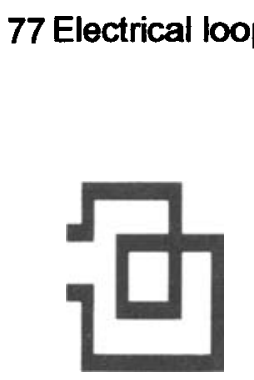

79 End of reel

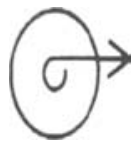

$\begin{array}{lr}\text { Concreteness: } & 1.60 \\ \text { Complexity: } & 2.38 \\ \text { Familiarity: } & 1.48 \\ \text { Meaningfulness: } & 1.43 \\ \text { Semantic Distance: } & 1.95 \\ \text { Complexity Metric: } & 3 \\ \text { Concept Agreement: } & 2.50 \\ \text { Name Agreement: } & 7.50 \\ & \text { maze }\end{array}$

Concreteness: $\quad 1.92$

Complexity:

Familiarity:

Meaningtulness:

2.45

1.70

1.65

Semantic Distance:

2.17

Complexity Metric:

3

Concept Agreement:

0.00

Name Agreement:
72 Earthing point

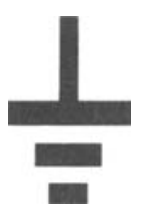

74 Eject

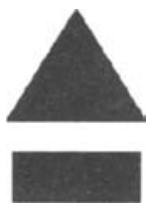

76 Electric transmission

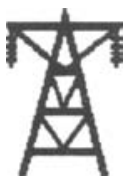

\section{Electrical precipitator}

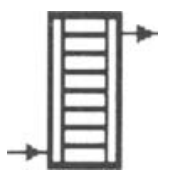

80 Engage pileraising roller

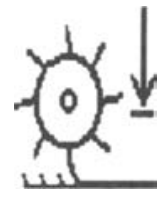

Concreteness:

2.18

Complexity: $\quad 2.00$

Familiarity: $\quad 2.58$

Meaningfulness: $\quad 2.18$

Semantic Distance: $\quad 1.58$

Complexity Metric: $\quad 4$

Concept Agreernent: $\quad 15.00$

Name Agreement: $\quad 15.00$

$\begin{array}{lr}\text { Concreteness: } & 2.40 \\ \text { Complexity: } & 1.45 \\ \text { Familiarity: } & 3.43 \\ \text { Meaningfulness: } & 2.85 \\ \text { Semantic Distance: } & 2.43 \\ \text { Complexity Metric: } & 2 \\ \text { Concept Agreement: } & 30.00 \\ \text { Name Agreement: } & 30.00\end{array}$

Concreteness: $\quad 4.40$

Complexity: $\quad 3.63$

Familiarity: $\quad 4.45$

Meaningfulness: $\quad 4.20$

Semantic Distance: $\quad 3.48$

Complexity Metric: $\quad 22$

Concept Agreement: $\quad 0.00$

Name Agreement: $\quad 55.00$ electricity pylons

$\begin{array}{lr}\text { Concreteness: } & 2.25 \\ \text { Complexity: } & 2.65 \\ \text { Familiarity: } & 1.92 \\ \text { Meaningfulness: } & 2.16 \\ \text { Semantic Distance: } & 1.17 \\ \text { Complexity Metric: } & 14 \\ \text { Concept Agreement: } & 0.00 \\ \text { Name Agreement: } & 15.00 \\ & \text { stairs }\end{array}$

Concreteness: $\quad 2.32$

Complexity: $\quad 3.20$

Familiarity: $\quad 2.08$

Meaningfulness: $\quad 1.79$

Semantic Distance: $\quad 1.92$

Complexity Metric: $\quad 18$

Concept Agreement: $\quad 0.00$

Name Agreement: $\quad 12.50$

water mill 
APPENDIX (Continued)

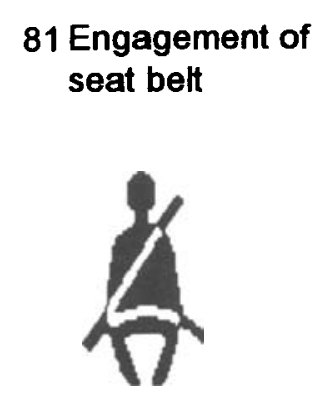

83 Equipotentials
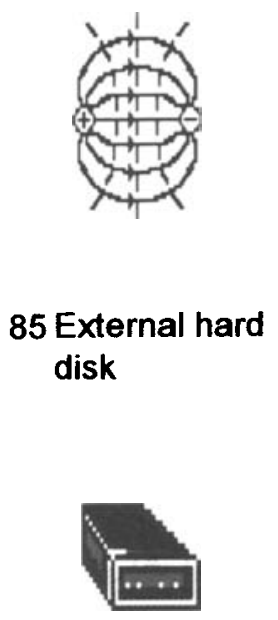

87 Fallout shelter

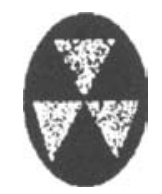

89 Farm kitchen

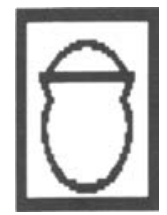

$\begin{array}{lr}\text { Concreteness: } & 4.15 \\ \text { Complexity: } & 2.85 \\ \text { Familiarity: } & 3.90 \\ \text { Meaningfulness: } & 4.27 \\ \text { Semantic Distance: } & 4.26 \\ \text { Complexity Metric: } & 5 \\ \text { Concept Agreement: } & 80.00 \\ \text { Name Agreement: } & 80.00\end{array}$

\begin{tabular}{lr} 
Concreteness: & 2.43 \\
Complexity: & 3.82 \\
Familiarity: & 3.15 \\
Meaningfulness: & 2.98 \\
Semantic Distance: & 2.78 \\
Complexity Metric: & 21 \\
Concept Agreement: & 0.00 \\
Name Agreement: & 30.00 \\
\multicolumn{2}{c}{ magnetic field }
\end{tabular}

$\begin{array}{lr}\text { Concreteness: } & 3.08 \\ \text { Complexity: } & 3.15 \\ \text { Familiarity: } & 1.98 \\ \text { Meaningfulness: } & 1.63 \\ \text { Semantic Distance: } & 1.86 \\ \text { Complexity Metric: } & 10 \\ \text { Concept Agreement: } & 2.50 \\ \text { Name Agreement: } & 2.50\end{array}$

$\begin{array}{lr}\text { Concreteness: } & 2.85 \\ \text { Complexity: } & 2.65 \\ \text { Familiarity: } & 3.55 \\ \text { Meaningfuiness: } & 2.58 \\ \text { Semantic Distance: } & 1.52 \\ \text { Complexity Metric: } & 4 \\ \text { Concept Agreement: } & 0.00 \\ \text { Name Agreement: } & 20.00 \\ & \text { radiation }\end{array}$

$\begin{array}{lr}\text { Concreteness: } & 2.30 \\ \text { Complexity: } & 2.32 \\ \text { Familiarity: } & 1.88 \\ \text { Meaningfulness: } & 1.67 \\ \text { Semantic Distance: } & 1.14 \\ \text { Complexity Metric: } & 3 \\ \text { Concept Agreement: } & 0.00 \\ \text { Name Agreement: } & 10.00 \\ & \text { pot }\end{array}$

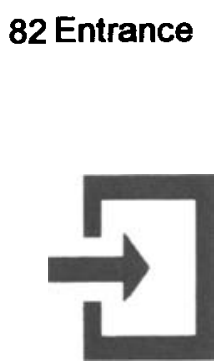

$\begin{array}{ll}\text { Concreteness: } & 2.38 \\ \text { Complexity: } & 1.70 \\ \text { Familiarity: } & 2.60 \\ \text { Meaningfulness: } & 260\end{array}$

Semantic Distance: $\quad 3.36$

Complexity Metric: 3

Concept Agreement: $\quad 45.00$

Name Agreement: $\quad \mathbf{4 5 . 0 0}$

$\begin{array}{lr}\text { Concreteness: } & 2.58 \\ \text { Complexity: } & 3.15 \\ \text { Familiarity: } & 1.78 \\ \text { Meaningfulness: } & 1.35 \\ \text { Semantic Distance: } & 2.13 \\ \text { Complexity Metric: } & 6 \\ \text { Concept Agreement: } & 2.50 \\ \text { Name Agreement: } & 2.50\end{array}$

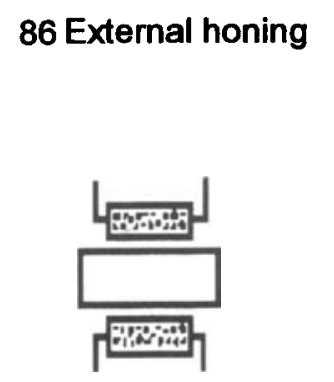

$\begin{array}{lr}\text { Concreteness: } & 2.30 \\ \text { Complexity: } & 2.90 \\ \text { Familiarity: } & 2.10 \\ \text { Meaningfulness: } & 1.77 \\ \text { Semantic Distance: } & 1.66 \\ \text { Complexity Metric: } & 7 \\ \text { Concept Agreement: } & 0.00 \\ \text { Name Agreement: } & 7.50 \\ & \text { electrical }\end{array}$

\section{Fan}

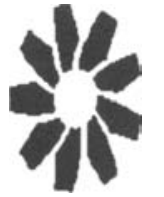

90 Fast

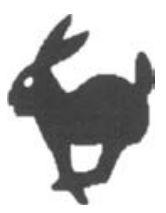

Concreteness: $\quad 2.58$

Complexity: $\quad 2.40$

Familiarity: $\quad 2.35$

Meaningfulness: $\quad 2.30$

Semantic Distance: $\quad 3.36$

Complexity Metric: $\quad 9$

Concept Agreement: $\quad 17.50$

Name Agreement: $\quad 17.50$

$\begin{array}{lr}\text { Concreteness: } & 4.72 \\ \text { Complexity: } & 2.10 \\ \text { Familiarity: } & 3.73 \\ \text { Meaningfulness: } & 4.10 \\ \text { Semantic Distance: } & 3.02 \\ \text { Complexity Metric: } & 1 \\ \text { Concept Agreement: } & 15.00 \\ \text { Name Agreement: } & 52.50 \\ & \text { rabbit }\end{array}$


APPENDIX (Continued)

$\begin{array}{llr}\text { 91 Fast forward } & \text { Concreteness: } & 3.28 \\ & \text { Complexity: } & 1.23 \\ & \text { Familiarity: } & 4.27 \\ & \text { Meaningfulness: } & 3.95 \\ & \text { Semantic Distance: } & 3.38 \\ & \text { Complexity Metric: } & 2 \\ & \text { Concept Agreement: } & 62.50 \\ & \text { Name Agreement: } & 62.50\end{array}$

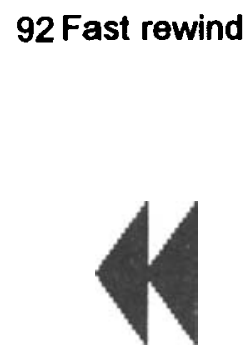

$\begin{array}{lr}\text { Concreteness: } & 3.05 \\ \text { Complexity: } & 1.10 \\ \text { Familiarity: } & 4.25 \\ \text { Meaningfulness: } & 3.70 \\ \text { Semantic Distance: } & 3.00 \\ \text { Complexity Metric: } & 2 \\ \text { Concept Agreement: } & 50.00 \\ \text { Name Agreement: } & 50.00\end{array}$

$\begin{array}{llr}93 \text { Female } & \text { Concreteness: } & 2.15 \\ & \text { Complexity: } & 2.73 \\ & \text { Familiarity: } & 4.75 \\ & \text { Meaningfulness: } & 4.60 \\ & \text { Semantic Distance: } & 2.14 \\ & \text { Complexity Metric: } & 3 \\ & \text { Concept Agreement: } & 60.00 \\ & \text { Name Agreement: } & 60.00\end{array}$

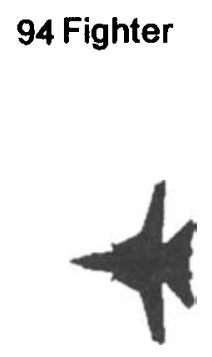

$\begin{array}{lr}\text { Concreteness: } & 4.50 \\ \text { Complexity: } & 1.88 \\ \text { Familiarity: } & 4.33 \\ \text { Meaningfulness: } & 3.90 \\ \text { Semantic Distance: } & 3.69 \\ \text { Complexity Metric: } & 1 \\ \text { Concept Agreement: } & 56.00 \\ \text { Name Agreement: } & 55.00\end{array}$

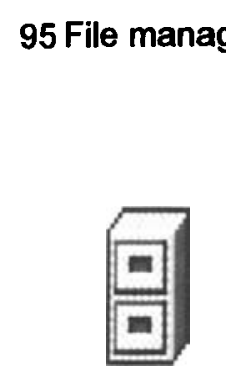

$\begin{array}{lr}\text { Concreteness: } & 4.55 \\ \text { Complexity: } & 2.53 \\ \text { Familiarity: } & 4.00 \\ \text { Meaningfulness: } & 3.35 \\ \text { Semantic Distance: } & 3.24 \\ \text { Complexity Metric: } & 7 \\ \text { Concept Agreement: } & 10.00 \\ \text { Name Agreement: } & 47.50 \\ & \text { files }\end{array}$

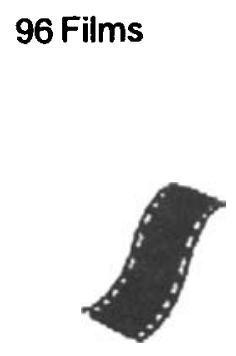

$\begin{array}{lr}\text { Concreteness: } & 4.60 \\ \text { Complexity: } & 1.70 \\ \text { Familiarity: } & 4.55 \\ \text { Meaningfulness: } & 4.20 \\ \text { Semantic Distance: } & 4.33 \\ \text { Complexity Metric: } & 1 \\ \text { Concept Agreement: } & 80.00 \\ \text { Name Agreement: } & 80.00\end{array}$

\section{Films}

$\begin{array}{lr}\text { Concreteness: } & 4.47 \\ \text { Complexity: } & 3.92 \\ \text { Familiarity: } & 3.67 \\ \text { Meaningfulness: } & 3.07 \\ \text { Semantic Distance: } & 2.79 \\ \text { Complexity Metric: } & 12 \\ \text { Concept Agreement: } & 2.50 \\ \text { Name Agreement: } & 25.00\end{array}$

Marilyn Monroe

$\begin{array}{clr}99 \text { Fixed bed } & \text { Concreteness: } & 2.00 \\ \text { reactor } & \text { Complexity. } & 2.75 \\ & \text { Familiarity: } & 1.87 \\ & \text { Meaningtuiness: } & 1.70 \\ & \text { Semantic Distance: } & 1.32 \\ & \text { Complexity Metric: } & 14 \\ & \text { Concept Agreement: } & 0.00 \\ & \text { Name Agreement: } & 12.50\end{array}$

100 Focal plane

\begin{tabular}{lr} 
Concreteness: & 2.70 \\
Complexity: & 1.32 \\
Familiarity: & 3.35 \\
Meaningfulness: & 3.42 \\
Semantic Distance: & 1.62 \\
Complexity Metric: & 2 \\
Concept Agreement: & 0.00 \\
Name Agreement: $\quad 42.50$ \\
\multicolumn{2}{c}{ underground }
\end{tabular}




\section{APPENDIX (Continued)}

\begin{tabular}{|c|c|c|c|c|c|}
\hline \multirow{3}{*}{$\begin{array}{l}101 \text { Food } \\
\text { processing } \\
\text { industry }\end{array}$} & Concreteness: & 3.18 & \multirow{2}{*}{102 Football } & Concreteness: & 4.93 \\
\hline & Complexity: & 2.15 & & Complexity: & 3.03 \\
\hline & Familiarity: & 2.69 & & Familiarity: & 4.53 \\
\hline & Meaningfulness: & 3.18 & & Meaningfulness: & 3.97 \\
\hline & Semantic Distance: & 2.76 & & Semantic Distance: & 4.83 \\
\hline & Complexity Metric: & 4 & & Complexity Metric: & 9 \\
\hline & Concept Agreement: & 0.00 & & Concept Agreement: & 75.00 \\
\hline & Name Agreement: & 45.00 & & Name Agreement: & 75.00 \\
\hline \multirow{9}{*}{103 Football ground } & Concreteness: & 2.90 & \multirow{9}{*}{104 Frog } & Concreteness: & 4.80 \\
\hline & Complexity: & 2.15 & & Complexity: & 3.45 \\
\hline & Familiarity: & 2.48 & & Familiarity: & 3.28 \\
\hline & Meaningfulness: & 2.40 & & Meaningfulness: & 3.05 \\
\hline & Semantic Distance: & 2.31 & & Semantic Distance: & 4.88 \\
\hline & Complexity Metric: & 8 & & Complexity Metric: & 8 \\
\hline & Concept Agreement: & 12.50 & & Concept Agreement: & 50.00 \\
\hline & Name Agreement: & 32.50 & & Name Agreement: & 50.00 \\
\hline & & rugby & & & \\
\hline \multirow[t]{9}{*}{105 Fun } & Concreteness: & 3.57 & \multirow[t]{9}{*}{106 Gastropods } & Concreteness: & 2.95 \\
\hline & Complexity: & 1.87 & & Complexity: & 1.56 \\
\hline & Familiarity: & 4.15 & & Familiarity: & 3.10 \\
\hline & Meaningfulness: & 3.48 & & Meaningfulness: & 3.10 \\
\hline & Semantic Distance: & 3.02 & & Semantic Distance: & 1.74 \\
\hline & Complexity Metric: & 3 & & Complexity Metric: & 3 \\
\hline & Concept Agreement: & 0.00 & & Concept Agreement: & 2.50 \\
\hline & Name Agreement: & 36.00 & & Name Agreement: & 72.50 \\
\hline & & happy & & & cream \\
\hline \multirow[t]{9}{*}{107 Gents toilets } & Concreteness: & 4.35 & \multirow[t]{9}{*}{108 Go rapidly } & Concreteness: & 4.35 \\
\hline & Complexity: & 1.35 & & Complexity: & 1.93 \\
\hline & Familiarity: & 4.95 & & Familiarity: & 4.05 \\
\hline & Meaningfulness: & 4.17 & & Meaningfulness: & 4.05 \\
\hline & Semantic Distance: & 3.33 & & Semantic Distance: & 3.71 \\
\hline & Complexity Metric: & 2 & & Complexity Metric: & 1 \\
\hline & Concept Agreement: & 55.00 & & Concept Agreement: & 0.00 \\
\hline & Name Agreement: & 55.00 & & Name Agreement: & 45.00 \\
\hline & & & & & running \\
\hline \multirow[t]{8}{*}{109 Graph } & Concreteness: & 3.63 & \multirow[t]{8}{*}{110 Gravel pit } & Concreteness: & 3.60 \\
\hline & Complexity: & 3.30 & & Complexity: & 1.50 \\
\hline & Familiarity: & 3.53 & & Familiarity: & 2.85 \\
\hline & Meaningfulness: & 3.48 & & Meaningfulness: & 2.68 \\
\hline & Semantic Distance: & 4.12 & & Semantic Distance: & 2.02 \\
\hline & Complexity Metric: & 12 & & Complexity Motric: & \\
\hline & Concept Agreement: & 52.00 & & Concept Agreement: & 0.00 \\
\hline & Name Agreement: & 52.00 & & Name Agreement: & $\begin{array}{r}82.50 \\
\text { digging }\end{array}$ \\
\hline
\end{tabular}


APPENDIX (Continued)

\begin{tabular}{|c|c|c|}
\hline 111 Handle with care & Concreteness: & 2.95 \\
\hline & Complexity: & 26 \\
\hline & Familiarity. & 3. \\
\hline & Meaningfulness: & 2.5 \\
\hline & Semantic Distance: & \\
\hline & Complexity Metric: & \\
\hline & Concept Agreement: & \\
\hline & Name Agreement: & 15 \\
\hline & & holdi \\
\hline $113 \mathrm{He}$ & Concreteness: & \\
\hline manufacturing & Complexity: & \\
\hline & Familiarity: & 3.2. \\
\hline & Meaningfuiness: & 2. \\
\hline & Sernantic Distance: & 2.1: \\
\hline & Complexity Metric: & \\
\hline & Concept Agreement: & 0. \\
\hline & Name Agreement: & 32.50 \\
\hline 115 Hie & Concreteness: & 2.43 \\
\hline & Complexity: & 2. \\
\hline & Familiarity. & 2.6 \\
\hline & Meaningfulness: & 2.7 \\
\hline & Semantic Distance: & 2 \\
\hline & Complexity Metric: & 10 \\
\hline & Concept Agreement: & 5.0 \\
\hline & Name Agroement: & 25 \\
\hline & & nily t \\
\hline
\end{tabular}

117 Hiking trail

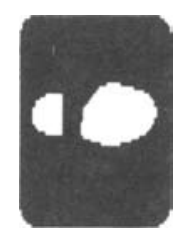

119 Inject reacting resin

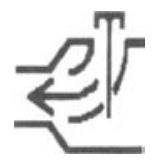

$\begin{array}{lr}\text { Concreteness: } & 4.10 \\ \text { Complexity: } & 1.53 \\ \text { Familiarity. } & 3.38 \\ \text { Meaningfulness: } & 3.18 \\ \text { Semantic Distance: } & 2.81 \\ \text { Complexity Metric: } & 3 \\ \text { Concept Agreement: } & 5.00 \\ \text { Name Agreement: } & 37.50 \\ & \text { footprint }\end{array}$

Concreteness:

Complexity.

Familiarity.

2.10

3.45

1.80

Meaningfuiness:

Semantic Distance:

Complexity Metric:

Concept Agreement:

Name Agreement:

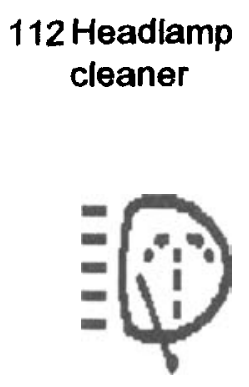

Concreteness:

3.10

2.95

Familiarity: $\quad 2.75$

Meaningfulness: $\quad 2.40$

Semantic Distance: $\quad 3.03$

Complexity Metric: $\quad 10$

Concept Agreement: $\quad 15.00$

Name Agreement: $\quad 15.00$

$\begin{array}{lr}\text { Concreteness: } & 4.72 \\ \text { Complexity: } & 1.90 \\ \text { Familiarity: } & 4.05 \\ \text { Meaningfulness: } & 3.85 \\ \text { Semantic Distance: } & 4.00 \\ \text { Complexity Metric: } & 6 \\ \text { Concept Agreement: } & 2.50 \\ \text { Name Agreement: } & 80.00 \\ & \text { helicopter }\end{array}$

$116 \mathrm{High}$ water level in laundry

118 Information
120 Insert object linking and embedding file

$\begin{array}{lr}\text { Concreteness: } & 2.73 \\ \text { Complexity: } & 3.40 \\ \text { Familiarity: } & 2.00 \\ \text { Meaningfuiness: } & 2.05 \\ \text { Semantic Distance: } & 1.13 \\ \text { Complexity Metric: } & 12 \\ \text { Concept Agreement: } & 0.00 \\ \text { Name Agreement: } & 20.00 \\ & \text { desert }\end{array}$
machines

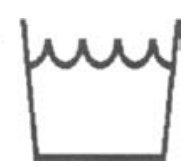

$\begin{array}{lr}\text { Concreteness: } & 3.20 \\ \text { Complexity: } & 2.07 \\ \text { Familiarty: } & 3.05 \\ \text { Meaningfuiness: } & 2.80 \\ \text { Semantic Distance: } & 1.33 \\ \text { Complexty Metric: } & 4 \\ \text { Concept Agreement: } \quad 0.00 \\ \text { Name Agreement: } \quad 25.00 \\ & \text { directions }\end{array}$

3.85

Complexity: $\quad 1.63$

Familiarity: $\quad 3.85$

Meaningfulness: $\quad 3.36$

Semantic Distance: $\quad 2.62$

Complexity Metric: $\quad 2$

Concept Agreement: $\quad 5.00$

Name Agreement: $\quad 52.50$

water

3.20

2.07

3.05

2.80

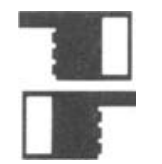

4

0.00

5.00

rections

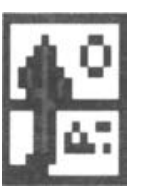

05

6

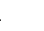


APPENDIX (Continued)

121 Inspect

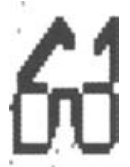

123 lonising radiation

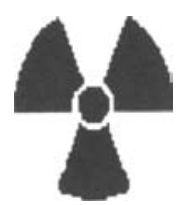

125 Iron

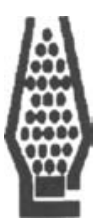

127 Justice

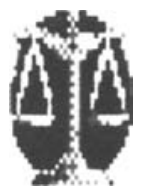

129 Laminate

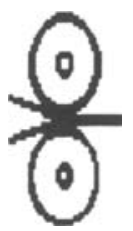

$\begin{array}{lr}\text { Concreteness: } & 4.70 \\ \text { Complexity: } & 2.33 \\ \text { Familiarity: } & 3.80 \\ \text { Meaningfulness: } & 3.80 \\ \text { Semantic Distance: } & 2.00 \\ \text { Complexity Metric: } & 6 \\ \text { Concept Agreernent: } & 2.50 \\ \text { Name Agreement: } & 65.00 \\ & \text { glasses }\end{array}$

Concreteness:

Complexity:

Familiarity:

Meaningfulness:

Semantic Distance:

Complexity Metric:

Concept Agreement:

Name Agreement:

50.00

1.53

4.50

4.10

2.02

4

50.00

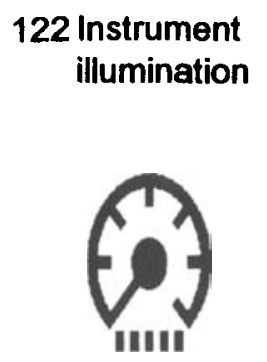

124 Iris diaphragm: Open

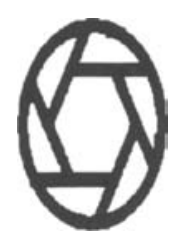

Concreteness: $\quad 3.55$

Complexity: $\quad 2.30$

Familiarity: $\quad 3.78$

Meaningtulness: $\quad 3.32$

Semantic Distance: $\quad 2.00$

Complexity Metric: $\quad 14$

Concept Agroement: $\quad 0.00$

Name Agreement: $\quad 30.00$

speedometer
50.00

2.38

3.36

2.42

1.90

1.86

32

0.00

5.00

container

Concreteness: $\quad 4.18$

Complexity: $\quad 3.90$

Familiarity: $\quad 3.88$

Meaningfuiness: $\quad 3.75$

Semantic Distance: $\quad 2.74$

Complexity Metric: $\quad 7$

Concept Agreement: $\quad 12.50$

Name Agreement: $\quad 42.50$

scales

$\begin{array}{lr}\text { Concreteness: } & 3.28 \\ \text { Complexity: } & 1.15 \\ \text { Familiarity: } & 1.92 \\ \text { Meaningfulness: } & 2.05 \\ \text { Semantic Distance: } & 2.15 \\ \text { Complexity Metric: } & 7 \\ \text { Concept Agreement: } & 2.50 \\ \text { Name Agreement: } & 17.70 \\ & \text { butterfly }\end{array}$

$\begin{array}{lr}\text { Concreteness: } & 2.85 \\ \text { Complexity: } & 2.17 \\ \text { Familiarity: } & 2.48 \\ \text { Meaningfulness: } & 1.92 \\ \text { Semantic Distance: } & 2.85 \\ \text { Complexity Metric: } & 7 \\ \text { Concept Agreement: } & 0.00 \\ \text { Name Agreement: } & 15.00 \\ & \text { football }\end{array}$

126 Jacketed reacto

Concreteness:

2.13

Complexity:

4.15

Familiarity:

1.38

Meaningfulness: $\quad 1.35$

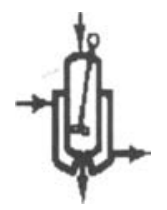

Semantic Distance: $\quad 1.46$

Complexity Metric: $\quad 15$

Concept Agreement: $\quad 0.00$

Name Agreement: $\quad 2.50$

Concreteness:

2.88

Complexity:

4.20

Familiarity:

1.65

Meaningfulness: $\quad 2.00$

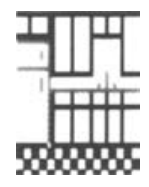

Semantic Distance:

2.79

Complexity Metric:

46

Concept Agreement: $\quad 25.00$

Name Agreement: $\quad 25.00$

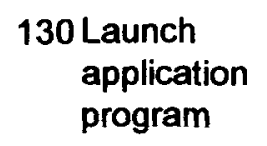

Concreteness:
Complexity:

4.68

Familiarity.

2.93

3.18

Meaningfulness: $\quad 3.85$

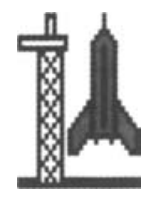

Semantic Distance: $\quad 3.29$

Complexity Metric: $\quad 21$

Concept Agreement: $\quad 0.00$

Name Agreement: $\quad 42.50$

rocket 
APPENDIX (Continued)

131 Library

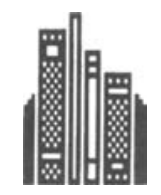

133 Lift
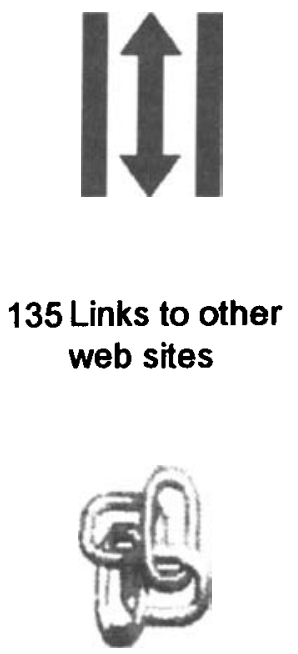

$\begin{array}{lr}\text { Concreteness: } & 4.13 \\ \text { Complexity: } & 3.30 \\ \text { Familiarity: } & 3.05 \\ \text { Meaningfulness: } & 3.23 \\ \text { Semantic Distance: } & 3.43 \\ \text { Complexity Metric: } & 13 \\ \text { Concept Agreement: } & 27.50 \\ \text { Name Agreement: } & 27.50\end{array}$

Concreteness:

268

Complexity.

2.03

Familiarity.

Meaningfulness:

2.42

2.49

Semantic Distance:

Complexity Metric:

Concept Agreement:

Name Agreement:

twa-way

Concreteness: $\quad 3.47$

Complexity: $\quad 3.30$

Familiarity. $\quad 3.02$

Meaningfulness: $\quad 2.90$

Semantic Distance: $\quad 2.12$

Complexity Metric: 8

Concept Agreement: $\quad 0.00$

Name Agreement: $\quad 40.00$

chain

Concreteness:

3.70

Complexity:

1.13

Familiarity:

3.93

Meaningfulness:

3.27

Semantic Distance: $\quad 3.24$

Complexity Metric: 2

Concept Agreement: $\quad 45.00$

Name Agreement: $\quad 45.00$

$\begin{array}{lr}\text { Concreteness: } & 4.65 \\ \text { Complexity: } & 3.30 \\ \text { Familiarity: } & 2.95 \\ \text { Meaningfulness: } & 3.35 \\ \text { Semantic Distance: } & 3.85 \\ \text { Complexity Metric: } & 12 \\ \text { Concept Agreement: } & 20.00 \\ \text { Name Agreement: } & 20.00\end{array}$

Name Agreement:

20.00

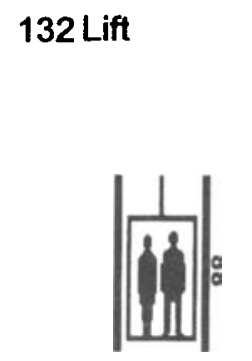

$\begin{array}{lr}\text { Concreteness: } & 4.45 \\ \text { Complexity: } & 3.05 \\ \text { Familiarity: } & 3.82 \\ \text { Meaningfulness: } & 3.98 \\ \text { Semantic Distance: } & 4.76 \\ \text { Complexity Metric: } & 8 \\ \text { Concept Agreement: } & 65.00 \\ \text { Name Agreement: } & 65.00\end{array}$

134 Line vessel

$\begin{array}{lr}\text { Concreteness: } & 2.08 \\ \text { Complexity: } & 2.23 \\ \text { Familiarity: } & 1.70 \\ \text { Meaningfulness: } & 1.85 \\ \text { Semantic Distance: } & 1.62 \\ \text { Complexity Metric: } & 1 \\ \text { Concept Agreement: } & 15.00 \\ \text { Name Agreement: } & 17.50 \\ & \text { down }\end{array}$

136 Lock

Concreteness:

4.58

Complexity:

1.75

Familiarity:

4.03

Meaningfulness:

3.96

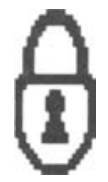

Semantic Distance:

4.57

Complexity Metric:

3

Concept Agreement: $\quad 70.00$

Name Agreement: $\quad 70.00$
139 Mace

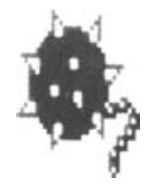

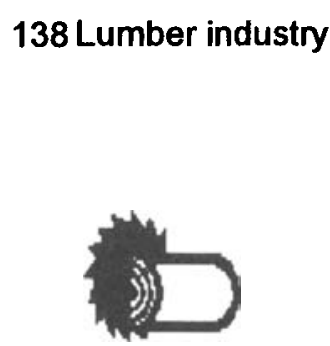

Concreteness:

3.23

Familiarity

2.98

Meaningfulness:

2.45

Semantic Distance:

3.08

Complexity Metric:

3.26

Name Agreement: $\quad \mathbf{2 5 . 0 0}$

saw

\section{Macrobiotics}

Concreteness:

3.43

Complexity:

2.20

Familiarity:

4.42

Meaningfulness:

3.97

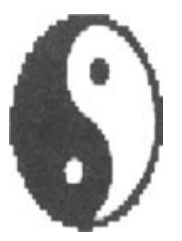

Semantic Distance:

1.24

Complexity Metric:

Concept Agreement: $\quad 0.00$

Name Agreement: $\quad 12.50$

yin yang 


\section{APPENDIX (Continued)}

\section{Magnify}

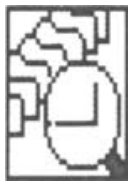

143 Male

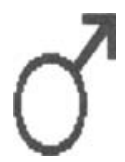

145 Measure

147 Mineral spring

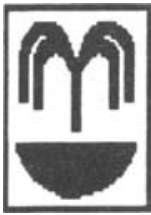

149 Module

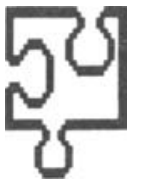

$\begin{array}{lr}\text { Concreteness: } & 3.48 \\ \text { Complexity: } & 3.88 \\ \text { Familiarity: } & 2.20 \\ \text { Meaningfulness: } & 2.40 \\ \text { Semantic Distance: } & 3.64 \\ \text { Complexity Metric: } & 11 \\ \text { Concept Agreement: } & 15.00 \\ \text { Name Agreement: } & 30.00 \\ & \text { clock }\end{array}$

Concroteness:

3.37

Complexity:

1.23

Familiarity:

4.75

Meaningfulness:

Semantic Distance

Complexity Metric:

Concept Agreement:

4.43

2.14

3

62.50

Name Agreement:

62.50

$\begin{array}{lr}\text { Concreteness: } & 3.43 \\ \text { Complexity: } & 3.30 \\ \text { Familiarity: } & 2.48 \\ \text { Meaningfulness: } & 2.40 \\ \text { Semantic Distance: } & 2.90 \\ \text { Complexity Metric: } & 12 \\ \text { Concept Agreement: } & 7.50 \\ \text { Name Agreement: } & 7.50\end{array}$

$\begin{array}{lr}\text { Concreteness: } & 3.28 \\ \text { Complexity: } & 2.15 \\ \text { Familiarity: } & 3.02 \\ \text { Meaningfulness: } & 3.35 \\ \text { Semantic Distance: } & 2.26 \\ \text { Complexity Metric: } & 7 \\ \text { Concept Agreement: } & 5.00 \\ \text { Name Agreement: } & 65.00 \\ & \text { fountain }\end{array}$

Concreteness:

3.87

Complexity:

2.50

Familiarity:

3.43

Meaningfulness:

3.67

Semantic Distance:

Complexity Metric

1.50

Concept Agreement:

0.00

Name Agreement:
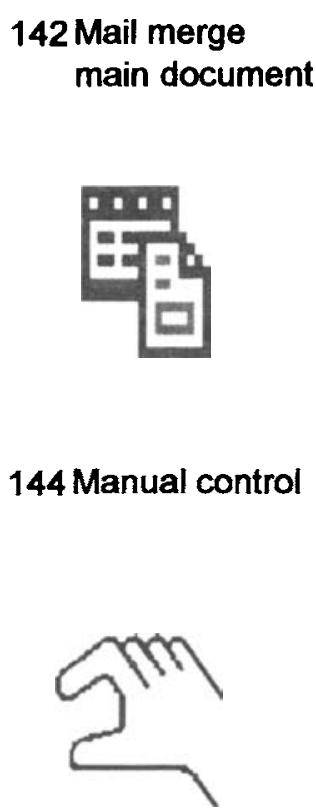

146 Microphone

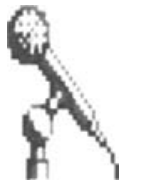

148 Missile in flight

Concreteness:

2.80

Familiarity:

1.25

2.72

Meaningfulness: $\quad 2.75$

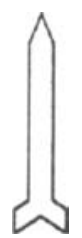

Semantic Distance:

2.55

Complexity Metric:

1

Concept Agreement:

45.00

Name Agreement:

45.00

\section{Mouse}

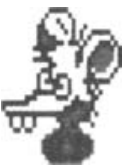

Concreteness:

4.68

Complexity:

3.50

Familiarity:

3.22

Meaningfulness:

3.50

Semantic Distance: $\quad 4.57$

Complexty Metric: $\quad 16$

Concept Agreement: $\quad 62.50$

Name Agreement: $\quad 62.50$ 
APPENDIX (Continued)

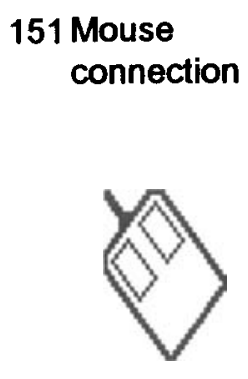

153 Museum

155 Navy

157 No entry

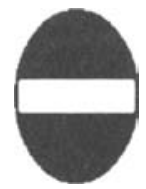

159 No!

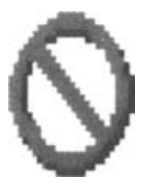

$\begin{array}{lr}\text { Concreteness: } & 3.53 \\ \text { Complexity: } & 2.37 \\ \text { Familiarity: } & 3.40 \\ \text { Meaningfulness: } & 3.22 \\ \text { Semantic Distance: } & 3.52 \\ \text { Complexity Metric: } & 4 \\ \text { Concept Agreement: } & 22.50 \\ \text { Name Agreement: } & 22.50\end{array}$

\begin{tabular}{lr} 
Concreteness: & 2.15 \\
Complexity: & 2.73 \\
Familiarity: & 2.00 \\
Meaningfulness: & 2.00 \\
Semantic Distance: & 1.98 \\
Complexity Metric: & 3 \\
Concept Agreement: & 0.00 \\
Name Agreement: & 7.50 \\
\multicolumn{2}{c}{ Greek temple }
\end{tabular}

$\begin{array}{lr}\text { Concreteness: } & 4.23 \\ \text { Complexity: } & 1.40 \\ \text { Familiarity: } & 4.32 \\ \text { Meaninglulness: } & 4.13 \\ \text { Semantic Distance: } & 3.26 \\ \text { Complexity Metric: } & 3 \\ \text { Concept Agreement: } & 5.00 \\ \text { Name Agreement: } & 67.50 \\ & \text { anchor }\end{array}$

Concreteness: $\quad 4.43$

Complexity: $\quad \$ 1.13$

Familiarity: $\quad 4.87$

Meaningfulness: $\quad 4.40$

Semantic Distance: $\quad 2.02$

Complexity Metric: 2

Concept Agreement: $\quad 82.50$

Name Agreement: $\quad 82.50$

$\begin{array}{lr}\text { Concreteness: } & 3.85 \\ \text { Complexity: } & 2.06 \\ \text { Familiarity: } & 4.70 \\ \text { Meaningfulness: } & 3.95 \\ \text { Semantic Distance: } & 2.07 \\ \text { Complexity Metric: } & 3 \\ \text { Concept Agreement: } & 17.50 \\ \text { Name Agreement: } & 17.50\end{array}$

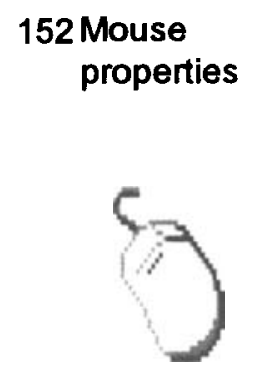

$\begin{array}{lr}\text { Concreteness: } & 4.25 \\ \text { Complexity: } & 3.25 \\ \text { Familiarity: } & 3.87 \\ \text { Meaningfulness: } & 2.93 \\ \text { Semantic Distance: } & 2.90 \\ \text { Complexity Metric: } & 4 \\ \text { Concept Agreement: } & 52.50 \\ \text { Name Agreement: } & 52.50\end{array}$

154 Naughty

$\begin{array}{lr}\text { Concreteness: } & 3.85 \\ \text { Complexity: } & 3.70 \\ \text { Familiarity: } & 2.83 \\ \text { Meaningfulness: } & 3.15 \\ \text { Semantic Distance: } & 3.14 \\ \text { Complexity Metric: } & 21 \\ \text { Concept Agreement: } & 0.00 \\ \text { Name Agreement: } & 87.50 \\ & \text { devil }\end{array}$

156 No entry

Concreteness:

4.65

Complexty:

1.60

Familiarity:

3.90

Meaningfulness: $\quad 3.97$

Semantic Distance: $\quad 2.79$

Complexity Metric: $\quad 1$

Concept Agreement: $\quad \mathbf{5 7 . 5 0}$

Name Agreement: $\quad \mathbf{5 7 . 5 0}$

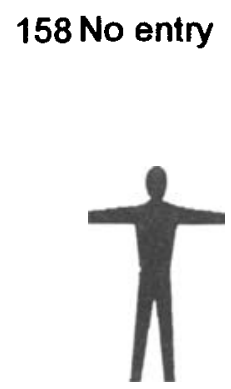

$\begin{array}{lr}\text { Concreteness: } & 3.97 \\ \text { Complexity: } & 1.45 \\ \text { Familiarity: } & 3.65 \\ \text { Meaningfulness: } & 3.27 \\ \text { Semantic Distance: } & 1.71 \\ \text { Complexty Metric: } & 1 \\ \text { Concept Agreement: } & 5.00 \\ \text { Name Agreement: } & 20.00 \\ & \text { man }\end{array}$

160 Noise

Concreteness:

2.70

Complexity:

3.18

Familiarity:

3.58

Meaningfulness: $\quad 3.08$

Semantic Distance: $\quad 2.40$

Complexity Metric: $\quad 1$

Concept Agreement: $\quad 15.00$

Name Agreement: $\quad 15.00$ 
APPENDIX (Continued)

$\begin{array}{clr}\text { 161 Non-ionising } & \text { Concreteness: } & 3.50 \\ \text { radiation } & \text { Complexty: } & 2.10 \\ & \text { Familiarty: } & 3.67 \\ & \text { Meaningfulness: } & 3.88 \\ ((1 .))) & \text { Semantic Distance: } & 1.59 \\ & \text { Complexty Metric: } & 8 \\ & \text { Concept Agreement: } & 15.00 \\ & \text { Name Agreement: } & 20.00 \\ & & \text { sound }\end{array}$

163 Open half-nut

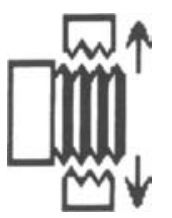

165 Open shade

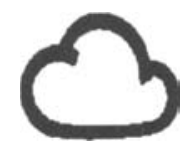

Concreteness:

Complexity:

Familiarity:

Meaningfulness:

Semantic Distance:

Complexity Metric:

Concept Agreement:

Name Agreement:

Concreteness:

Complexity:

Familiarity:

Meaningfulness:

Semantic Distance:

Complexity Metric:

Concept Agreement:

Name Agreement:
2.45

3.47

1.83

1.98

2.13

11

0.00

12.50

screw

4.05

1.04

4.23

4.05

1.64

1

0.00

77.50

cloud
162 Note

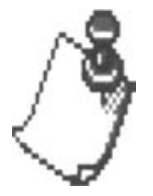

164 Open location

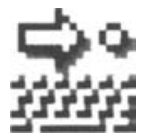

166 Opening of selvedge loops

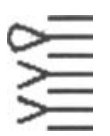

168 Paper industry

2.83

1.85

1.62

$\begin{array}{lr}\text { Semantic Distance: } & 1.26 \\ \text { Complexity Metric: } & 5\end{array}$

Concept Agreement: $\quad 0.00$

Name Agreement: $\quad 5.00$

circuit

169 Paradox

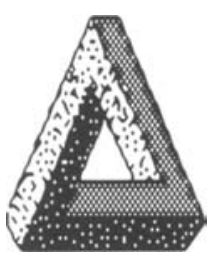

$\begin{array}{lr}\text { Concreteness: } & 2.55 \\ \text { Complexity: } & 3.72 \\ \text { Familiarity: } & 3.18 \\ \text { Meaningfulness: } & 2.25 \\ \text { Semantic Distance: } & 2.17 \\ \text { Complexity Metric: } & 3 \\ \text { Concept Agreement: } & 0.00 \\ \text { Name Agreement: } & 7.50 \\ & \text { illusion }\end{array}$

$\begin{array}{lr}\text { Concreteness: } & 4.45 \\ \text { Complexity: } & 3.32 \\ \text { Familiarity: } & 3.35 \\ \text { Meaningfulness: } & 3.08 \\ \text { Semantic Distance: } & 3.95 \\ \text { Complexity Metric: } & 5 \\ \text { Concept Agreement: } & 47.50 \\ \text { Name Agreement: } & 47.50\end{array}$

Concreteness: $\quad 2.23$

Complexity: $\quad 3.63$

Familiarity: $\quad 1.90$

Meaningfulness: $\quad 1.59$

Semantic Distance: $\quad 1.33$

Complexity Metric: $\quad 28$

Concept Agreement: $\quad 2.50$

Name Agreement: $\quad 5.00$

keyboard

Concreteness: $\quad 1.62$

Complexity: $\quad 2.90$

Familiarity: $\quad 1.50$

Meaningfulness: $\quad 1.35$

Semantic Distance: $\quad 1.68$

Complexity Metric: $\quad 12$

Concept Agreement: $\quad 0.00$

Name Agreement: $\quad 2.50$

$\begin{array}{lr}\text { Concreteness: } & 3.78 \\ \text { Complexity: } & 1.80 \\ \text { Familiarity: } & 3.00 \\ \text { Meaningfulness: } & 2.88 \\ \text { Semantic Distance: } & 2.71 \\ \text { Complexity Metric: } & 4 \\ \text { Concept Agreement: } & 2.50 \\ \text { Name Agreement: } & 35.00 \\ & \text { toilet paper }\end{array}$

170 Pause

Concreteness:

2.60

Complexity:

1.20

Familiarity:

3.28

Meaningfulness:

3.03

Semantic Distance: $\quad 2.07$

Complexity Metric: $\quad 2$

Concept Agreement: $\quad \mathbf{3 7 . 5 0}$

Name Agreement: $\quad 37.50$ 
171 Peace

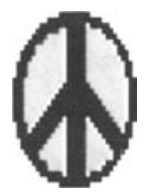

175 Polishing process of fabrics

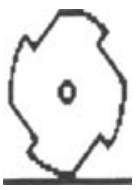

177 Press tool

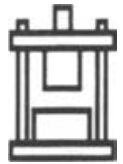

$\begin{array}{lr}\text { Concreteness: } & 3.62 \\ \text { Complexity: } & 2.10 \\ \text { Familiarity: } & 4.35 \\ \text { Meaningfulness: } & 3.80 \\ \text { Semantic Distance: } & 1.98 \\ \text { Complexity Metric: } & 4 \\ \text { Concept Agreement: } & 42.50 \\ \text { Name Agreement: } & 42.50\end{array}$

Concreteness:

2.15

Complexity:

Familiarity.

Meaningfulness:

Semantic Distance:

Complexity Metric:

Concept Agreement:

Name Agreement:

$\begin{array}{lr}\text { Concreteness: } & 2.98 \\ \text { Complexity: } & 1.95 \\ \text { Familiarity: } & 2.45 \\ \text { Meaningfulness: } & 2.03 \\ \text { Semantic Distance: } & 1.32 \\ \text { Complexity Metric: } & 3 \\ \text { Concept Agreement: } & 0.00 \\ \text { Name Agreement: } & 15.00\end{array}$

saw

\begin{tabular}{lr} 
Concreteness: & 2.65 \\
Complexity: & 3.20 \\
Familiarity: & 2.00 \\
Meaningfulness: & 1.63 \\
Semantic Distance: & 2.38 \\
Complexity Metric: & 9 \\
Concept Agreement: & 2.50 \\
Name Agreement: & 5.00 \\
& \multicolumn{2}{c}{ machinery }
\end{tabular}

Concreteness:

2.50

Complexity:

3.62

Familiarity:

2.20

Meaningfulness:

2.70

Semantic Distance:

2.60

Complexity Metric: $\quad 16$

Concept Agreement: $\quad 0.00$

Name Agreement:

20.00
172 Picnic area

Concreteness:
Complexity:

4.00

Familiarity:

2.23

3.90

Meaningfulness:

4.12

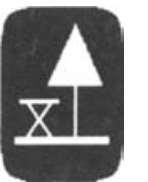

Semantic Distance:

3.90

Complexity Metric:

6

Concept Agreement: $\quad \mathbf{5 7 . 5 0}$

Name Agreement: $\quad \mathbf{5 7 . 5 0}$

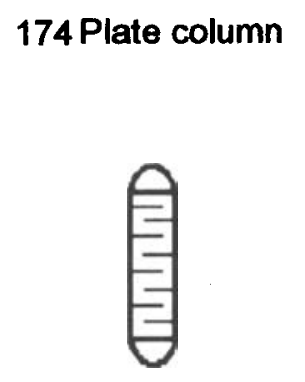

176 Portable files

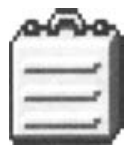

178 Product

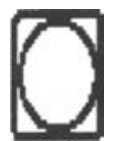
energy
Concreteness: $\quad 2.83$

Complexity: $\quad 2.30$

Familiarity: $\quad 2.73$

Meaningfulness: $\quad 2.08$

Semantic Distance: $\quad 1.69$

Complexity Metric: $\quad 11$

Concept Agreement: $\quad 2.50$

Name Agreement: $\quad 10.00$ thermometer

$\begin{array}{lr}\text { Concreteness: } & 4.83 \\ \text { Complexity: } & 2.60 \\ \text { Familiarity: } & 3.80 \\ \text { Meaningfulness: } & 3.75 \\ \text { Semantic Distance: } & 2.57 \\ \text { Complexity Metric: } & 9 \\ \text { Concept Agreement: } & 0.00 \\ \text { Name Agreement: } & 45.00 \\ & \text { suitcase }\end{array}$

Concreteness: $\quad 2.25$

Complexity: $\quad 1.40$

Familianty: $\quad 2.12$

Meaningfulness: $\quad 1.68$

Semantic Distance: $\quad 1.02$

Complexity Metric: 2

Concept Agreement: $\quad 0.00$

Name Agreement: $\quad 7.50$

button

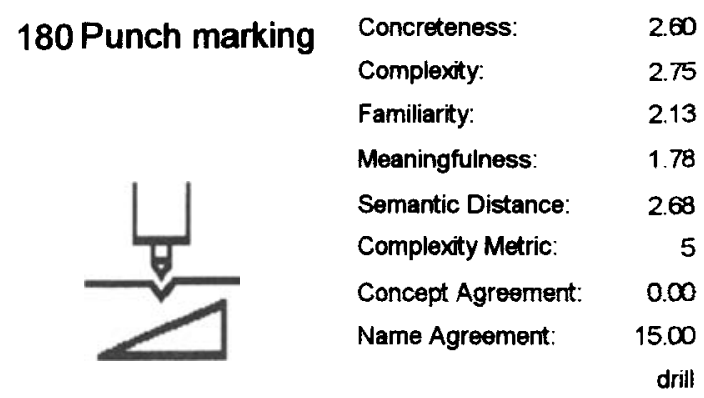




\section{APPENDIX (Continued)}

$\begin{array}{clr}\text { 181 Radiation of } & \text { Concreteness: } & 3.23 \\ \text { laser apparatus } & \text { Complexity: } & 2.53 \\ & \text { Familiarity: } & 3.13 \\ & \text { Meaningfulness: } & 3.18 \\ & \text { Semantic Distance: } & 1.83 \\ & \text { Complexity Metric: } & 25 \\ \text { Concept Agreement: } & 2.50 \\ & \text { Name Agreement: } & 57.50 \\ & & \text { sun }\end{array}$

183 Recycle

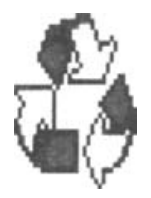

185 Rinse

187 Roman
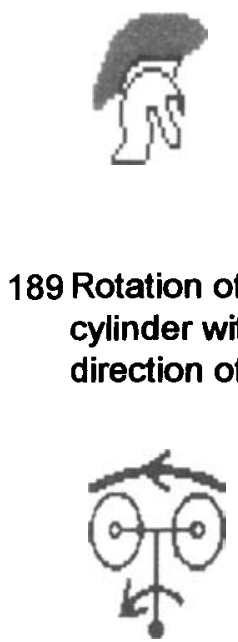

$\begin{array}{lr}\text { Concreteness: } & 3.27 \\ \text { Complexity: } & 3.05 \\ \text { Familiarity: } & 4.42 \\ \text { Meaningfulness: } & 4.25 \\ \text { Semantic Distance: } & 3.26 \\ \text { Complexity Metric: } & 9 \\ \text { Concept Agreement: } & 72.50 \\ \text { Name Agreement: } & 72.50\end{array}$

Concreteness: $\quad 1.65$

Complexity: $\quad 3.40$

Familiarity: $\quad 1.65$

Meaningfulness: $\quad 1.55$

Semantic Distance: $\quad 1.55$

Complexity Metric: $\quad 7$

Concept Agreement: $\quad 0.00$

$\begin{array}{lr}\text { Concreteness: } & 3.93 \\ \text { Complexity: } & 3.22 \\ \text { Familiarity: } & 2.97 \\ \text { Meaningfulness: } & 3.08 \\ \text { Semantic Distance: } & 3.62 \\ \text { Complexity Metric: } & 3 \\ \text { Concept Agreement: } & 25.00 \\ \text { Name Agreement: } & 25.00\end{array}$

Concreteness: $\quad 1.65$

Complexty: $\quad 3.40$

Familiarity. $\quad 1.48$

Semantic Distance: $\quad 1.87$

Complexity Metric: $\quad 10$

Concept Agreement: $\quad 0.00$

Name Agreement: $\quad 7.50$

bike
Name Agreement: $\quad 2.50$

Meaningfulness: $\quad 1.45$

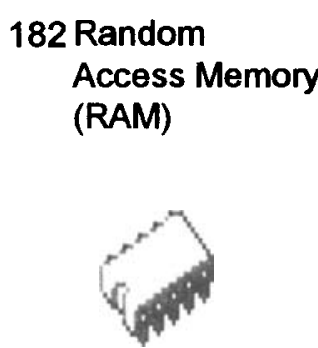

184 Return to home page
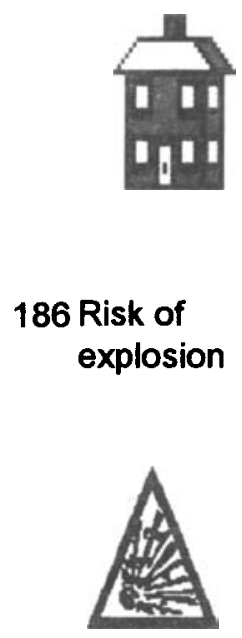

Concreteness:

3.65

Complexity:

3.72

Familiarity:

3.30

Meaningfuiness:

3.15

Semantic Distance: $\quad 2.76$

Complexity Metric: $\quad 26$

Concept Agreement: $\quad 15.00$

Name Agreement: $\quad 15.00$

70

15

65

$\infty$

6

.00

chip

78

.95

3.90

.75

.43

13

.50

house

$\begin{array}{lr}\text { Concreteness: } & 1.90 \\ \text { Complexity: } & 4.00 \\ \text { Familiarity: } & 1.53 \\ \text { Meaningfulness: } & 1.50 \\ \text { Semantic Distance: } & 1.70 \\ \text { Complexty Metric: } & 9 \\ \text { Concept Agreement: } & 0.00 \\ \text { Name Agreement: } & 5.00 \\ & \text { forces }\end{array}$

Concreteness: $\quad 2.82$

Complexity: $\quad 1.95$

Familiarity: $\quad 2.74$

Meaningfulness: $\quad 2.58$

Semantic Distance: $\quad 2.17$

Complexity Metric: $\quad 9$

Concept Agreement: $\quad 7.50$

Name Agreement: $\quad 27.50$

(n)


APPENDIX (Continued)

$\begin{array}{llr}191 \text { Safe } & \text { Concreteness: } & 4.83 \\ & \text { Complexity: } & 3.18 \\ & \text { Familiarity. } & 3.90 \\ & \text { Meaningfulness: } & 4.22 \\ & \text { Semantic Distance: } & 4.62 \\ & \text { Complexity Metric: } & 12 \\ & \text { Concept Agreement: } & 77.50 \\ & \text { Name Agreement: } & 77.50\end{array}$

193 Safety isolating transformer

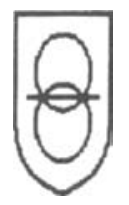

195 Scythe

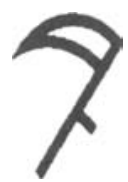

197 Search

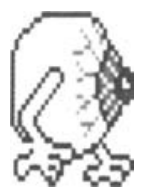

199 Search

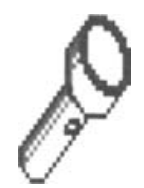

Concreteness: $\quad 2.17$

Complexty: $\quad 255$

Meaningfulness: $\quad 1.53$

Semantic Distance: $\quad 1.25$

Complexity Metric: $\quad 4$

Concept Agreement: $\quad 0.00$

Name Agreement: $\quad 2.50$

Concreteness: $\quad 3.38$

Complexity: $\quad 1.52$

Familiarity: $\quad 3.02$

Meaningfulness: $\quad 2.78$

Semantic Distance: $\quad 4.23$

Complexity Metric: $\quad 3$

Concept Agreement: $\quad 62.50$

Name Agreement: $\quad 62.50$

$\begin{array}{lr}\text { Concreteness: } & 3.20 \\ \text { Complexity: } & 3.95 \\ \text { Familiarity: } & 2.15 \\ \text { Meaningfulness: } & 2.40 \\ \text { Semantic Distance: } & 2.70 \\ \text { Complexity Metric: } & 13 \\ \text { Concept Agreement: } & 0.00 \\ \text { Name Agreement: } & 32.50 \\ & \text { eye }\end{array}$

Concreteness: $\quad 4.62$

Complexity: $\quad 2.58$

Familiarity: $\quad 3.65$

Meaningfulness: $\quad 3.75$

Semantic Distance: $\quad 2.43$

Complexity Metric: 4

Concept Agreement: $\quad 0.00$

Name Agreement: $\quad 70.00$

torch
Familiarity. $\quad 2.10$
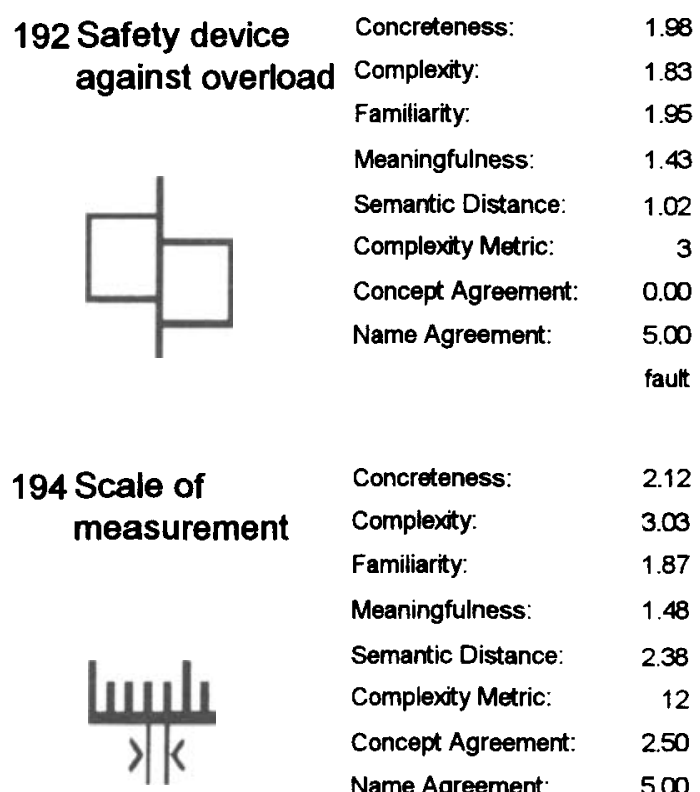

$\begin{array}{lr}\text { Concreteness: } & 2.12 \\ \text { Complexity: } & 3.03 \\ \text { Familiarity: } & 1.87 \\ \text { Meaningfulness: } & 1.48 \\ \text { Semantic Distance: } & 2.38 \\ \text { Complexity Metric: } & 12 \\ \text { Concept Agreement: } & 2.50 \\ \text { Name Agreement: } & 5.00 \\ & \text { distance }\end{array}$

196 Sea mine decoy

$\begin{array}{lr}\text { Concreteness: } & 1.80 \\ \text { Complexity: } & 2.62 \\ \text { Familiarity: } & 1.58 \\ \text { Meaningfulness: } & 1.30 \\ \text { Semantic Distance: } & 1.54 \\ \text { Complexity Motric: } & 7 \\ \text { Concept Agreement: } & 0.00 \\ \text { Name Agreement: } & 2.50\end{array}$

198 Search

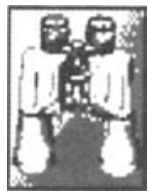

200 Select irregular area

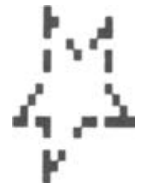

Concreteness:

4.85

Complexity:

3.70

Familiarity:

3.83

Meaningfulness: $\quad 3.85$

Semantic Distance: $\quad 3.29$

Complexity Metric: $\quad 21$

Concept Agreement: $\quad 0.00$

Name Agreement: $\quad \$ 5.00$

binoculars

Concreteness: $\quad 2.20$

Complexity: $\quad 2.85$

Familiarity: $\quad 2.28$

Meaningfulness: $\quad 1.88$

Semantic Distance: $\quad 1.79$

Complexity Metric: $\quad 10$

Concept Agreement: $\quad 0.00$

Name Agreement: $\quad 20.00$

83

thent

\section{2}

7

8

38

2

50




\section{APPENDIX (Continued)}

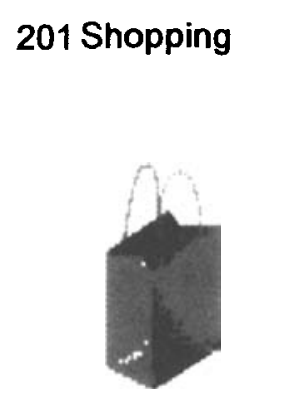

203 Smooth edges

205 Spade

207 Spark plug

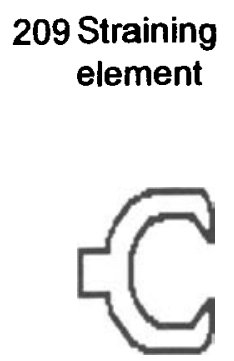

$\begin{array}{lr}\text { Concreteness: } & 4.83 \\ \text { Complexity: } & 3.12 \\ \text { Familiarity: } & 4.03 \\ \text { Meaningfulness: } & 3.90 \\ \text { Semantic Distance: } & 4.10 \\ \text { Complexity Metric: } & 7 \\ \text { Concept Agreement: } & 15.00 \\ \text { Name Agreement: } & 60.00 \\ & \mathrm{bag}\end{array}$

Concreteness: $\quad 2.95$

Complexity:

4.30

Familiarity:

2.42

Meaningfulness: $\quad 2.18$

Semantic Distance: $\quad 1.50$

Complexity Metric: 41

Concept Agreement: $\quad 2.50$

Name Agreement: $\quad 12.50$

paint

Concreteness: $\quad 2.75$

Complexity:

Familiarity:

Meaningfulness: $\quad 1.98$

Semantic Distance: $\quad 3.62$

Complexity Metric: 2

Concept Agreement: $\quad 2250$

Name Agreement: $\quad 22.50$

$\begin{array}{lr}\text { Concreteness: } & 2.35 \\ \text { Complexity: } & 2.83 \\ \text { Familiarity: } & 3.60 \\ \text { Meaningfulness: } & 3.20 \\ \text { Semantic Distance: } & 4.55 \\ \text { Complexity Metric: } & 15 \\ \text { Concept Agreement: } & 42.50 \\ \text { Name Agreement: } & 42.50\end{array}$

Concreteness: $\quad 2.33$

Complexity: $\quad 1.80$

Familiarity:

Meaningfulness:

Semantic Distance:

Complexity Metric:

Concept Agreement:

Name Agreement:
1.80
1.95

1.62

1.28

1

0.00

5.00

tool

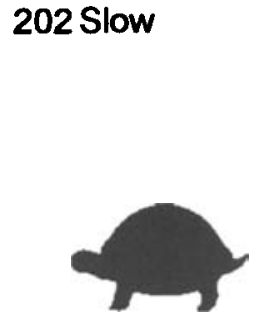

204 Sound

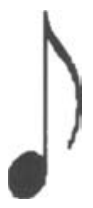

206 Spark coilignition element

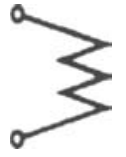

208 Sterilizer

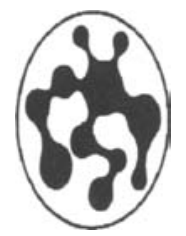
210 Suction removal of trimmed edges

Concreteness:

Complexity:

Familiarity:

Meaningfulness:

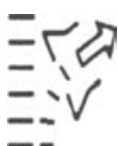

Semantic Distance:

Complexity Metric:

Concept Agreement:

Name Agreement:
1.95

3.35

4.72

1.70

3.45

3.53

3.26

1

15.00

62.50

turtie

4.35

1.30

4.60

4.52

3.53

1

2.50

75.00

music

2.25

2.27

2.55

2.17

1.95

3

0.00

15.00

electricity

1.85

3.40

1.90

1.73

1.36

2

7.50

bacteria

2.49
0.00 
APPENDIX (Continued)

211 Surgery

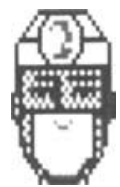

213 Tape recorder

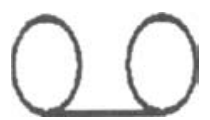

215 Thin ice

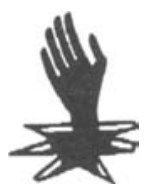

217 Timber
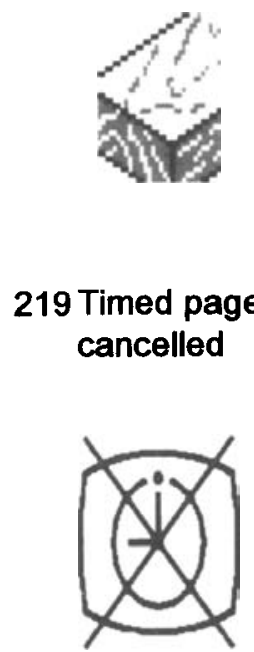

$\begin{array}{lr}\text { Concreteness: } & 4.45 \\ \text { Complexity: } & 3.70 \\ \text { Familiarity: } & 3.10 \\ \text { Meaningfulness: } & 3.60 \\ \text { Semantic Distance: } & 3.45 \\ \text { Complexity Metric: } & 18 \\ \text { Concept Agreement: } & 0.00 \\ \text { Name Agreement: } & 40.00 \\ & \text { doctor }\end{array}$

$\begin{array}{lr}\text { Concreteness: } & 3.10 \\ \text { Complexity: } & 1.45 \\ \text { Familiarity: } & 3.30 \\ \text { Meaningfulness: } & 2.78 \\ \text { Semantic Distance: } & 2.69 \\ \text { Complexity Metric: } & 3 \\ \text { Concept Agreement: } \quad 15.00 \\ \text { Name Agreement: } \quad 32.50 \\ \end{array}$

Concreteness:

3.87

Complexity.

2.75

Familiarity:

3.00

Meaningfulness:

3.92

Semantic Distance:

3.74

Complexity Metric:

7

Concept Agreement:

70.00

Name Agreement:

70.00

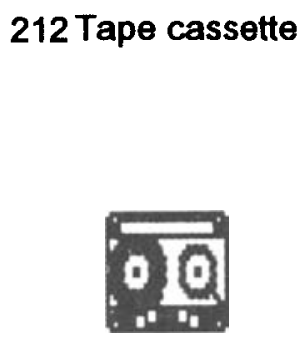

214 Temperature

Concreteness:
Complexity:

4.60

Familiarity:

1.18

4.70

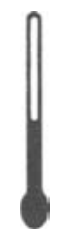

Meaningfulness:

4.25

Semantic Distance: $\quad 4.33$

Complexity Metric:

Concept Agreernent:

Name Agreement:

50.00

50.00

$\begin{array}{lr}\text { Concreteness: } & 2.63 \\ \text { Complexity: } & 1.63 \\ \text { Familiarity: } & 3.13 \\ \text { Meaningfulness: } & 2.75 \\ \text { Semantic Distance: } & 2.95 \\ \text { Complexity Metric: } & 4 \\ \text { Concept Agreement: } & 12.50 \\ \text { Name Agreement: } & 12.50\end{array}$

Concreteness:

3.75

Complexity:

1.58

Familiarity:

3.95

Meaningfulness: $\quad 3.80$

Semantic Distance: $\quad 3.55$

Complexity Metric: $\quad 1$

Concept Agreement: $\quad 32.50$

Name Agreement: $\quad 50.00$

timer

\section{Toolbox}

3.00

Complexity:

1.98

Familiarity.

2.35

Meaningfuiness

2.60

Semantic Distance:

Complexity Metric:

Concept Agreement: $\quad 10.00$

Name Agreement: $\quad 15.00$
Concreteness: $\quad 4.80$

Complexity: $\quad 2.55$

Familiarity: $\quad 3.28$

Meaningfulness: $\quad 3.73$

Semantic Distance: $\quad 3.50$

Complexity Metric: $\quad 9$

Concept Agreement: $\quad \mathbf{4 7 . 5 0}$

Name Agreement: $\quad \mathbf{4 7 . 5 0}$ 


\section{APPENDIX (Continued)}

\section{Topic}

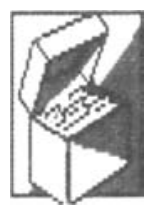

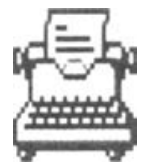

\section{Vertebrates}
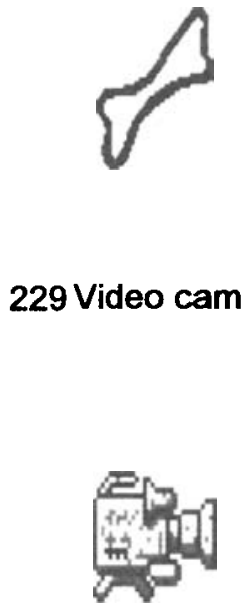

$\begin{array}{lr}\text { Concreteness: } & 4.63 \\ \text { Complexity: } & 3.15 \\ \text { Familiarity: } & 3.50 \\ \text { Meaningfulness: } & 2.75 \\ \text { Semantic Distance: } & 1.88 \\ \text { Complexity Metric: } & 12 \\ \text { Concept Agreement: } & 0.00 \\ \text { Name Agreement: } & 32.50 \\ & \text { files }\end{array}$

Concreteness:

3.97

Complexity.

2.77

Familiarity:

Meaningfulness:

Semantic Distance:

Complexity Metric:

Concept Agreement:

Name Agreement:

4.65

4.75

3.45

3

47.50

47.50

$\begin{array}{lr}\text { Concreteness: } & 4.93 \\ \text { Complexity: } & 3.03 \\ \text { Familiarity: } & 3.88 \\ \text { Meaningfulness: } & 3.85 \\ \text { Semantic Distance: } & 4.90 \\ \text { Complexity Metric: } & 36 \\ \text { Concept Agreement: } & 75.00 \\ \text { Name Agreement: } & 75.00\end{array}$

\section{Concreteness:}

Complexity:

Familiarity:

Meaningfulness:

Semantic Distance:

Complexity Metric:

Concept Agreement:

Name Agreement:

$$
\begin{array}{r}
2.80 \\
1.55 \\
2.45 \\
2.55 \\
2.12 \\
1 \\
0.00 \\
62.50 \\
\text { bone }
\end{array}
$$

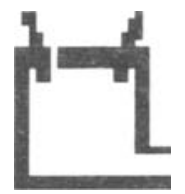

224 Tubular film die

Concreteness:
Complexity:

Familiarity:

Meaningfulness:

Semantic Distance:

Complexity Metric:

Concept Agreement:

Name Agreement:

3.83

1.70

3.43

3.80

1.50

6

0.00

47.50

tree

1.90

2.68

1.88

1.50

1.18

5

0.00

5.00

circuit

\section{Undo}

Concreteness:

2.62

Complexity:

1.35

Familiarity:

2.88

Meaningfulness:

2.80

Semantic Distance: $\quad 2.26$

Complexity Metric: $\quad 2$

Concept Agreement: $\quad 2.50$

Name Agreement: $\quad 27.50$

turn-around

\section{Vibrate}

230 Wall

Complexity:

4.83

3.28

Familiarity:

3.90

Meaningfulness:

3.92

Sernantic Distance:

$4 . \infty$

Complexity Metric

9

Concept Agreement: $\quad \mathbf{5 7 . 5 0}$

Name Agreement:

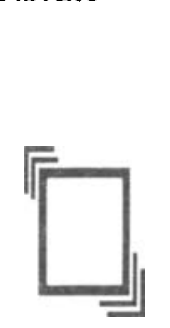

Concreteness:

2.02

Complexity:

2.40

Familiarity:

1.80

Meaningfuiness: $\quad 1.57$

Semantic Distance: $\quad 2.76$

Complexity Metric: $\quad 7$

Concept Agreement: $\quad 5.00$

Name Agreement: $\quad 7.50$

expanding

Concreteness: $\quad 3.95$

Familiarity: $\quad 3.00$

Meaningfulness: $\quad 3.13$

Semantic Distance: $\quad 4.40$

Complexity Metric: $\quad 12$

Concept Agreement: $\quad 60.00$

Name Agreement: $\quad \infty 0.0$
Complexity: $\quad 2.78$ 

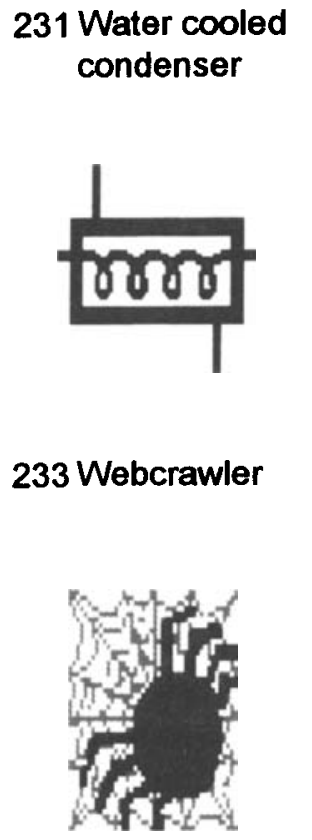

235 Wheel

\section{Winter sports area}

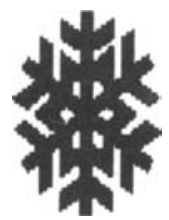

239 Zoom

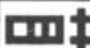

$\begin{array}{lr}\text { Concreteness: } & 2.85 \\ \text { Complexity: } & 2.70 \\ \text { Familiarity: } & 2.90 \\ \text { Meaningfulness: } & 2.18 \\ \text { Semantic Distance: } & 2.02 \\ \text { Complexity Metric: } & 8 \\ \text { Concept Agreement: } & 0.00 \\ \text { Name Agreement: } \quad 10.00 \\ & \text { electricity }\end{array}$

$\begin{array}{lr}\text { Concreteness: } & 4.58 \\ \text { Complexity: } & 3.70 \\ \text { Familiarity: } & 3.33 \\ \text { Meaningfulness: } & 3.47 \\ \text { Semantic Distance: } & 3.14 \\ \text { Complexty Metric: } & 41 \\ \text { Concept Agreement: } & 0.00 \\ \text { Name Agreement: } & 52.50 \\ & \text { spider }\end{array}$

Concreteness: $\quad 4.00$

Complexity: $\quad 3.18$

Familiarity: $\quad 2.83$

Meaningfulness: $\quad \mathbf{2 . 4 0}$

Semantic Distance: $\quad 4.48$

Complexity Metric: $\quad 16$

Concept Agreement: $\quad 35.00$

Name Agreement: $\quad 35.00$

$\begin{array}{lr}\text { Concreteness: } & 3.87 \\ \text { Complexity. } & 2.97 \\ \text { Familiarity: } & 4.45 \\ \text { Meaningfulness: } & 4.25 \\ \text { Semantic Distance: } & 2.24 \\ \text { Complexity Metric: } & 18 \\ \text { Concept Agreement: } & 0.00 \\ \text { Name Agreement: } & 35 . \infty 0 \\ & \text { snowflake }\end{array}$

Concreteness: $\quad 2.05$ Complexity: $\quad 2.87$

Familiarity: $\quad 1.73$

Meaningfulness: $\quad 1.60$

Semantic Distance: $\quad 1.10$

Complexity Metric: $\quad 7$

Concept Agreement: $\quad 0.00$

Name Agreement: $\quad 7.50$

radio

$\begin{array}{lr}\text { Concreteness: } & 3.13 \\ \text { Complexity: } & 2.55 \\ \text { Familiarity: } & 2.70 \\ \text { Meaningfulness: } & 2.40 \\ \text { Semantic Distance: } & 1.50 \\ \text { Complexity Metric: } & 1 \\ \text { Concept Agreement: } & 0.00 \\ \text { Name Agreement: } & 22.50 \\ & \text { tunnel }\end{array}$

234 Weight

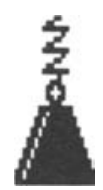

236 Windscreen demisting and defrosting
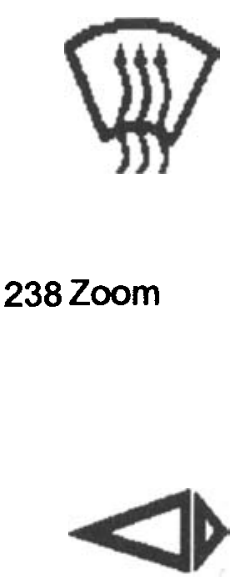

$\begin{array}{lr}\text { Concreteness: } & 3.03 \\ \text { Complexity: } & 3.08 \\ \text { Familiarity: } & 2.05 \\ \text { Meaningfulness: } & 1.97 \\ \text { Semantic Distance: } & 3.19 \\ \text { Complexity Metric: } & 3 \\ \text { Concept Agreement: } & 15.00 \\ \text { Name Agreement: } & 15.00\end{array}$

$\begin{array}{lr}\text { Concreteness: } & 3.50 \\ \text { Complexity: } & 2.00 \\ \text { Familiarity: } & 3.90 \\ \text { Meaningfulness: } & 3.65 \\ \text { Semantic Distance: } & 2.88 \\ \text { Complexity Metric: } & 4 \\ \text { Concept Agreement: } & 40.00 \\ \text { Name Agreement: } & 40.00\end{array}$

$\begin{array}{lr}\text { Concreteness: } & 1.85 \\ \text { Complexity: } & 1.75 \\ \text { Familiarity: } & 1.95 \\ \text { Meaningfulness: } & 1.35 \\ \text { Semantic Distance: } & 1.76 \\ \text { Complexity Metric: } & 2 \\ \text { Concept Agreement: } & 0.00 \\ \text { Name Agreement: } & 5.00 \\ & \text { klte }\end{array}$

A large proportion of the symbols printed in the Appendix are within the public domain and are not copyrighted. Extracts from International Electrotechnical Standard IEC-417 (Icons $3,8,49,61,75,116,124,137,161,181,193,204,213$, and 219 ) are reproduced with the permission of the British Standards Institution. Complete editions of the standards can be obtained by post from BSI Customer Services, 389 Chiswick High Road, London W4 A4L, England. Icon 133 is reproduced with permission of the Federal Airports Corporation, Network Airports Group, 2 Lord Street, Botany, NSW 2019, Australia. 
Icons $7,10,17,21,23,46,50,57,63,65,66,71,73,74,91,92$, $108,111,115,131,136,145,149,150,160,170,223,228$, and 234 are reprinted with permission from The Icon Book: Visual Symbols for Computer Systems and Documentation, by William Horton, 1994, New York: Wiley. Copyright 1994 by John Wiley \& Sons, Inc. Icons 53, 95, 146, and 225 are reprinted with per- mission from the Microsoft Corporation, One Microsoft Way, Redmond, WA 98052-6399.

(Manuscript received December 5, 1997; revision accepted for publication April 23, 1998.) 